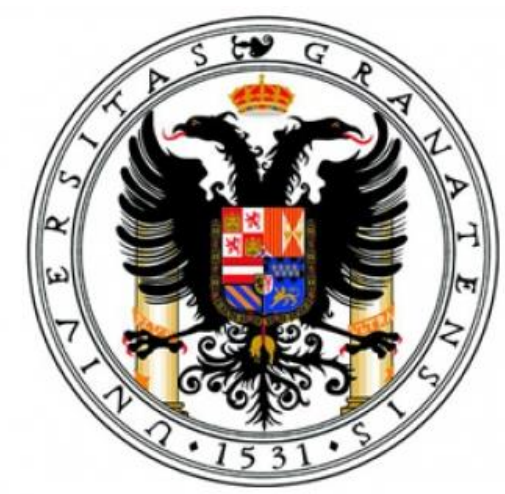

Universidad de Granada.

Máster en Filosofía Contemporánea. Curso 2013-2014

Trabajo de Fin de Máster

\title{
DEL NIHILISMO A LA VACUIDAD. LA AUTO-SUPERACIÓN DEL NIHILISMO EN LA FILOSOFÍA DE KEIJI NISHITANI
}

Alumno: Agustín Sánchez Cotta.

Tutora: Encarnación Ruiz Callejón.

Fecha: 17 de octubre de 2014.

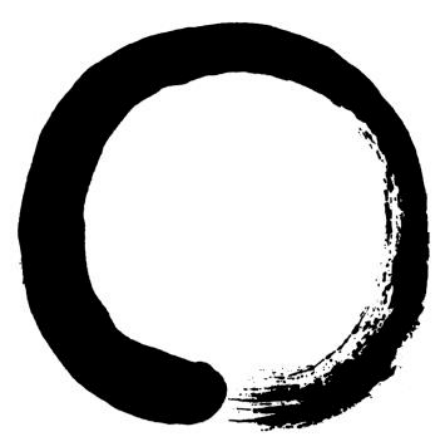


«En esto bajó sobre el altar, desde lo alto, una excelsa noble figura, sumida en un dolor inextinguible, y todos los muertos gritaron: « ¿Cristo!, ¿no hay un Dios?».

Él contestó: «No hay ninguno».

La sombra de cada difunto tembló por entero, y no sólo en su pecho; una tras otra quedaron aplastadas por ese fuerte temblor.»

Jean Paul, Alba del Nihilismo. 

Agradecimientos.

Deseo expresar mi agradecimiento a la profesora Encarnación Ruiz Callejón, cuya tutoría ha sido un apoyo indispensable para completar este Trabajo de Fin de Máster. 


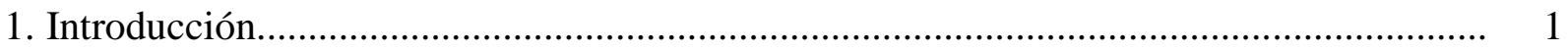

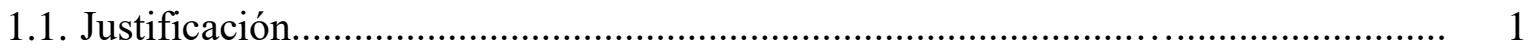

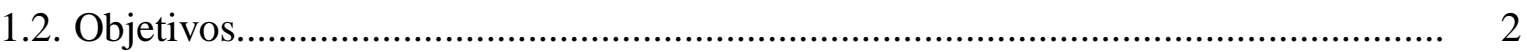

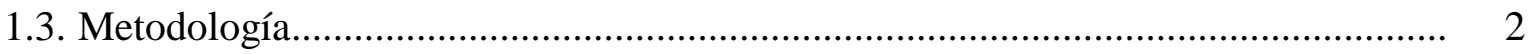

1.4. Estado de la cuestión................................................................................................. 5

2. El problema del nihilismo europeo en la filosofía de Friedrich Nietzsche...................... 8

2.1. El proceso histórico del nihilismo europeo............................................................ 8

2.2. Egepticismo: el germen nihilista inmerso en la metafísica europea........................ 12

2.3. la pesadez de la vida a través de la doctrina moral cristiana.................................. 15

2.4. Tipología y superación del nihilismo en Nietzsche................................................. 19

2.5. El nihilismo como análisis axio-antropológico de la cultura occidental.................. 25

3. La recepción del nihilismo europeo nietzscheano en la filosofía de Keiji Nishitani......... 26

3.1. Nishitani y su relación vital con el nihilismo europeo de Nietzsche........................ 26

3.2. Existenz. Metodología nietzscheana para una investigación del nihilismo............... 29

3.3. El cristianismo como causa principal del nihilismo........................................ 32

3.4. La muerte de Dios. El auge del nihilismo europeo o de la filosofía libre................. 37

4. La auto-superación atea del nihilismo europeo. Nietzsche a través de Nishitani.............. 39

4.1. Del diagnóstico a la auto-superación. Las tres transformaciones del espíritu........... 39

4.2. Nuevos valores. Voluntad de ilusión, sinceridad, amor fati y ego fatum ................. 43

4.3. El sentido del mundo Nietzscheano. El eterno retorno y el momento..................... 47

5. La auto-superación religiosa del nihilismo. El punto de vista de la vacuidad................... 48

5.1. El problema nihilista en el mundo occidental...................................................... 49

5.2. Ciencia, filosofía, religión y vida cotidiana............................................................. 51

5.3. El deseo de libertad y la orientación científica................................................ 54

5.4. La auto-superación religiosa del nihilismo. La vacuidad-śūnyatāa......................... 58 


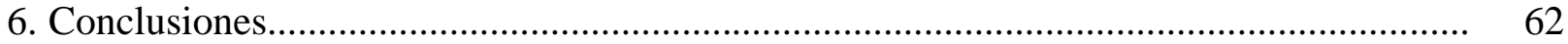

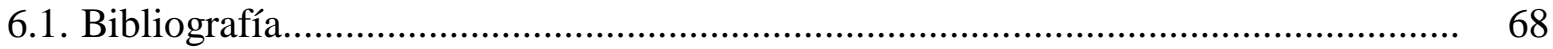




\section{Introducción}

\subsection{Justificación}

En este Trabajo de Fin de Máster pretendo abordar el planteamiento y la aclaración de una cuestión filosófica contemporánea: confrontar el diagnóstico de Nietzsche sobre la filosofía y la cultura occidental, que él califica como nihilismo, con su interpretación desarrollada por el filósofo japonés Keiji Nishitani, y una propuesta de superación. Se estudia aquí el nihilismo desde una perspectiva cultural circunscrita según Nietzsche al pensamiento europeo, que actualmente podríamos denominar como occidental; por otra parte la propuesta de superación de Nishitani se fundamenta en bases culturales no-occidentales, en concreto el pensamiento budista Zen. Considero que tales temas tanto en contenido como en profundidad rebasan los límites de las directrices de este trabajo de fin de máster. Es una labor inicial que puede dejar muchos aspectos sin resolver, y que serían de mi interés personal y profesional continuar si pudiera ser en una posterior tesis doctoral.

La hipótesis que se desea verificar consiste en comprobar si la filosofía budista de Keiji Nishitani proporciona una superación atea y religiosa ante el diagnóstico del nihilismo europeo, establecido por Friedrich Nietzsche. Nishitani se circunscribe a las tesis de este filósofo alemán del siglo XIX: la superación atea del nihilismo sería aquella terapia extraída de la filosofía de Nietzsche, y la superación religiosa sería aquella que el mismo autor japonés desarrolla. De hecho, la superación del nihilismo fue el objetivo principal de este filósofo de la segunda generación de la escuela de Kioto, y entendía esta cuestión como un problema existencialista, religioso y cultural. Consideraba que son los valores europeos y cristianos los causantes de esta problemática según su interpretación de Nietzsche, y por ello los valores culturales y religiosos japoneses podían aportar una solución. La razón por la cual se ha escogido a estos dos autores se justifica por mi intención de investigar el problema del nihilismo y sus posibles soluciones. En este caso Nietzsche es el primer 
autor donde surge el diagnóstico del nihilismo europeo, y Nishitani dedica toda su filosofía a investigar y superar el nihilismo, atendiendo a sobre todo a cómo lo desarrolló Nietzsche.

\subsection{Objetivos}

Objetivo principal. A la luz de una interpretación sobre el nihilismo europeo como problema cultural presente en la filosofía de Friedrich Nietzsche, profundizar en su interpretación a través de la filosofía de Keiji Nishitani e investigar las soluciones que dicho autor nos propone. Dilucidar si estamos ante una factible superación del nihilismo desde un punto de vista ateo y religioso.

Objetivos específicos.

1. Profundizar en el problema del nihilismo europeo según la filosofía de Nietzsche a través de su obra publicada y póstuma.

2. Reseñar la interpretación sobre el nihilismo nietzscheano a través de la filosofía de Keiji Nishitani.

3. Profundizar en la superación del nihilismo en la filosofía nietzscheana, interpretada por Keiji Nishitani. Esto sería una superación no-religiosa o atea del nihilismo europeo.

4. Profundizar en la superación del nihilismo que propone Keiji Nishitani en su filosofía. Esto sería una superación religiosa del nihilismo europeo.

5. Concluir el trabajo estableciendo qué aporta la filosofía de Keiji Nishitani al problema del nihilismo europeo formulado por Friedrich Nietzsche. Revelar posibles puntos de unión y contradicciones entre ambos autores.

\subsection{Metodología}

La metodología se ha centrado en realizar un estudio comparativo entre las obras fundamentales de ambos autores, siempre en relación con la temática del nihilismo europeo. En 
primer lugar, se han analizado aquellas obras de Nietzsche relacionadas con el nihilismo y aquellos estudios ya realizados sobre dicho autor y objeto de estudio. Dichas obras y estudios posteriores se han leído en su traducción española, incluso las notas póstumas. El listado de las obras leídas de Friedrich Nietzsche es el siguiente: el ensayo Sobre verdad y mentira en sentido extramoral (1873), y los libros Humano, demasiado humano (1878), La gaya ciencia (1883), Así habló Zaratustra, Más allá del bien y del mal (1885), La genealogía de la moral (1887), El Crepúsculo de los ídolos (1888), y los Fragmentos póstumos. El objetivo de este primer paso ha sido adquirir una interpretación completa del nihilismo europeo en Nietzsche como problema cultural.

En segundo lugar, se ha investigado la obra filosófica de Keiji Nishitani, en concreto las dos obras fundamentales del autor respecto al tema que nos ocupa: The Self-Overcoming of Nihilism y La Religión y la nada. Esta última se considera la obra principal del autor, y la primera es su trabajo monográfico centrado en el problema del nihilismo, donde de hecho se centra en la filosofía de Nietzsche. Los objetivos de este segundo paso han sido los siguientes:

- La interpretación que Nishitani desarrolla sobre el problema y la superación del nihilismo europeo en la filosofía de Nietzsche. Se ha considerado importante ya que define la posición del autor japonés ante la filosofía nietzscheana.

- La interpretación general y actual del nihilismo como problema cultural. Nishitani desarrolla una actualización del problema del nihilismo a finales del siglo XX usando como base las tesis de Nietzsche. Es necesario profundizar en la actualidad del nihilismo a ojos de Nishitani para entender su propuesta de superación.

- Por último analizar el punto de vista de la vacuidad, la tesis que Nishitani desarrolla como forma de superación religiosa del nihilismo.

En cuanto a la lectura de las obras de Nishitani, estas se han trabajado desde sus traducciones en inglés y en español. Las traducciones inglesas fueron supervisadas por el propio 
autor. No obstante, convendría aclarar que según James W. Heisig, el pensamiento de la escuela de Kioto no precisa dificultad lingüística en su traducción. No existe una verdadera brecha cultural en sus traducciones dado que los autores japoneses intentaron hacerse comprensibles a Occidente. (Heisig, 2002, p. 41-46)

En tercer lugar, se ha reflexionado sobre la relación entre los desarrollos filosóficos de ambos autores, según los textos leídos y los trabajos ya publicados sobre sus pensamientos. El objetivo de este tercer paso ha sido evidenciar posibles contradicciones que hicieran inviables una relación positiva entre Nietzsche y Nishitani. Si en el marco de un problema nietzscheano Nishitani ofrece una nueva interpretación y superación de la cuestión, es evidente que ambos pensamientos filosóficos deben poder entenderse ante el nihilismo como complementarios.

En cuarto lugar, se ha profundizado en el aspecto cultural y religioso de la filosofía de Nishitani, es decir, la doctrina budista en general y en especial su versión Zen. Esta profundización de corte antropológica ha sido necesaria para una mejor comprensión de la filosofía del pensador japonés.

En quinto y último lugar, se ha reflexionado sobre los aportes que el pensamiento de Nishitani ofrece al problema del nihilismo, sus nuevas perspectivas y soluciones. Intentando responder a la pregunta de si el sujeto humano enfrentado al problema nihilista puede superarlo a través de la filosofía nietzscheana, de la filosofía de Nishitani, a través de ambos, o a través de ninguno.

Me gustaría exponer en este apartado metodológico algunas aclaraciones sobre las citas de esta investigación. El sistema adoptado para citar fuentes y bibliografía secundaria de este trabajo ha sido el APA (American Psychological Association), siguiendo la guía expuesta por el Departamento II de filosofía de la Universidad de Granada en su página web. ${ }^{2}$

\footnotetext{
${ }^{2}$ http://www.ugr.es/ filosofia/recursos/innovacion/convo-2005/trabajo-escrito/formatos-de-citas.htm. Consultada por última vez el 4 de septiembre de 2014.
} 
Sobre algunas citas de Nishitani que incluían palabras en lengua nipona, hemos optado por escribirlas en su conversión a caracteres occidentales tal como reflejan sus propias traducciones al español y al inglés. Esa conversión es denominada transcripción romaji y en concreto el sistema usado en dichos trabajos, y referenciado en esta investigación, corresponde a las características del sistema Hepburn según el Gunkan, Diccionario de Kanjis japoneses (Ferres, 2001, p. 16-17). Es el sistema más extendido y reconocido por lingüistas japoneses para la transcripción del japonés a caracteres latinos.

Para terminar, quisiera reseñar que la bibliografía engloba todas las obras que durante esta investigación se han trabajado, con motivo de la mejor comprensión posible de sus contenidos. En este sentido en ellas se encuentran muchas obras que no han sido citadas a lo largo del trabajo, pero que han sido indispensables para su desarrollo. Pese a no estar citadas he creído necesario referenciarlas y por ello se encuentran en el listado final bibliográfico.

Abreviaturas de las obras y fragmentos de Nietzsche.

\section{AHZ Así habló Zaratustra.}

CI Crepúsculo de los ídolos.

FP Fragmentos Póstumos.

GC La gaya ciencia.

GM La genealogía de la moral.

HDH Humano, demasiado humano.

MBM Más allá del bien y del mal

SVM Sobre verdad y mentira en sentido extramoral.

\subsection{Estado de la cuestión}

Tanto Graham Parkes, en la introducción a la obra de Nishitani The Self-Overcoming of Nihilism (Parkes, xvi, p. 1990), como Franco Volpi en su obra El nihilismo (Volpi, 2004, p. 19), evidencian que desde la culminación del idealismo con la filosofía kantiana comienza una reflexión sobre el giro copernicano a finales del siglo XVIII y principios del XIX. En ella se muestra la 
problemática de entender toda la realidad desde el sujeto y la posibilidad de considerar lo externo a este como una nada. Ambos autores proponen esta idea como estado de la cuestión de dos obras filosóficas que tratan en su totalidad el problema del nihilismo. Sus ideas podrían desarrollarse con un trabajo del profesor Barroso Fernández titulado La Antropología filosófica ante el reto del nihilismo. Donde expone que Nietzsche va más allá de esta problemática destruyendo el último subterfugio del sujeto, demostrando que el individuo humano ejerce una razón dominada por un cúmulo de pasiones, instintos, deseos y necesidades. (Barroso, 2009, p. 146.) Esto evidentemente impide describir a la razón como una actividad pura que permita fundamentar la realidad a través del sujeto. De esta manera emerge el problema del nihilismo, el sinsentido de la realidad, la desaparición de toda referencia y fundamento.

El propio Nietzsche es consciente de esto y desarrolla el problema del nihilismo desde muchos ámbitos, hasta concluir que las consecuencias del sinsentido de la existencia provocan un pathos nihilista en el sujeto. El profesor Pérez Tapias especifica que esta cuestión no se restringe a la metafísica: «Durante siglos, la cultura occidental que emergió sobre esas apoyaturas ha incubado en su seno la enfermedad del nihilismo.» (Tapias, 2007, p. 33) Esto es, el problema del nihilismo ha avanzado desde la metafísica hacia la religión, y desde la religión hacia los ámbitos culturales, morales y axiológicos de la sociedad occidental. Diego Sánchez Meca sintetiza esta irrupción del nihilismo en la introducción al primer Volumen de los Fragmentos Póstumos:

\footnotetext{
"Porque con la muerte del Dios cristiano desaparece la autoridad incuestionable de la verdad y del bien. Nuestra vida deja de tener puntos de referencia absolutos, desaparecen las metas trascendentes y tanto los valores de la moral como las verdades del saber dejan de ser algo establecido y eternamente para siempre, para aparecer como meras creaciones de los hombres quienes colectivamente las han ido produciendo para satisfacer las exigencias de su existencia en el mundo. Es lo que Nietzsche piensa como «irrupción del nihilismo», el más inquietante de todos los huéspedes." (Sánchez Meca, 2010, p. 12)
}

En consecuencia, el estado de la cuestión del nihilismo nietzscheano significa la 
desaparición del sentido del mundo, la pérdida de fundamento de los valores metafísicos, morales y religiosos de la cultura europea, una desaparición de todo fundamento presente y posible de la vida humana.

Por otro lado, Sánchez Meca continúa indicando que la superación del nihilismo europeo también sería para Nietzsche una ascensión de la humanidad, luego es un problema, pero también una oportunidad de progreso. Este aspecto refleja dentro de la filosofía nietzscheana la ambivalencia del nihilismo. Por un lado, el fenómeno presenta el aspecto perjudicial de la falta de fundamento, pero por otro lado es también el punto de partida para el despertar de la historia de la humanidad: la liberación que experimenta el sujeto del mundo divino del cristianismo, el surgimiento de la auténtica libertad, la caída de la moral y de los valores metafísicos que pesaban al ser humano, y una transvaloración de todos los valores.

Ante esto podríamos preguntarnos por qué debemos considerar quizás simplemente el nihilismo como problema a superar, tal como se hace en esta investigación. Si continuamos la introducción de Sánchez Meca se nos revela la razón de entender el nihilismo como problema:

"«Porque algún sentido es mejor que ningún sentido, y porque el hombre prefiere incluso querer la nada a no querer en absoluto.» En otras palabras, tenderíamos a llenar ahora ese hueco que ha dejado el Dios muerto con otras máscaras, sin duda peores de la nada. Por eso continuamos siendo nihilistas, porque seguimos haciendo de la nada la guía de nuestra existencia." (Sánchez Meca, 2010, p. 12)

Permanecemos en el sinsentido y en lugar de justificar el ser justificamos la nada. En conclusión, el nihilismo establecido por Nietzsche es un problema actual para la sociedad occidental. Representa la existencia de unos valores culturales, científicos, filosóficos y religiosos que aun definen nuestro imaginario cultural y que ya no presentan fundamento. Lo que implica que existe una tarea pendiente: rellenar el vacío que ha dejado el sentido del mundo, superar el sinsentido y establecer una nueva posición de valores, superar el nihilismo europeo. 
Este es también el estado de la cuestión al que se enfrenta Keiji Nishitani cuando decide centrar su filosofía en superar el nihilismo. Nishitani nace exactamente en el mismo año de la muerte de Nietzsche y en el seno de un país occidentalizado, el Japón de principios de siglo XX. Desde su punto de vista, el problema del nihilismo atañe a una desvalorización de los valores que no solo implica a los países de cultura occidental, también afecta a aquellos cuya aculturación ha provocado la pérdida de sus propios valores supremos. La propuesta que desarrollará tras su profunda inmersión en la filosofía nietzscheana, será una nueva interpretación del sentido del mundo acorde con la filosofía de Nietzsche y basada en valores culturales no-occidentales, los valores de la cultura budista Zen japonesa y china.

En conclusión, la cuestión que se investiga en este trabajo de fin de máster es el análisis del nihilismo nietzscheano como punto de partida para analizar la superación del nihilismo en la filosofía de Keiji Nishitani.

\section{El problema del nihilismo europeo en la filosofía de Friedrich Nietzsche}

\subsection{El proceso histórico del nihilismo europeo}

El diagnóstico del nihilismo europeo en la filosofía de Friedrich Nietzsche podría ser denominado como la investigación de una serie de procesos hallados en la metafísica, la doctrina cristiana y los valores morales, en relación a cómo han influenciado el pensamiento y la cultura de la sociedad occidental. Una nueva lectura de la historia de Occidente. Un análisis que abarca cuestiones de muy diversos ámbitos, sin embargo, se centra en su aspecto como problema en la cultura occidental, cómo diagnóstico de un pathos perjudicial para el sujeto. Su descripción establece un inicio, una serie de factores, y supone un cúmulo de consecuencias que según su autor, que comienzan a manifestarse en su contemporaneidad y abarcarán los siglos XX y XXI (Nietzsche, FP. Vol IV, [1887-1888], 2007, 11 [119], p. 400-401). 
Sánchez Meca afirma que la filosofía de Nietzsche puede ser entendida cómo una evolución del diagnóstico de nihilismo. Un análisis que poco a poco se va afinando, mejorando y concretando hasta alcanzar los elementos precisos del problema en las obras finales y últimos fragmentos del autor. (Sánchez Meca, 2004, p. 107-108). Esta es la razón por la que encontramos en los Fragmentos Póstumos de Nietzsche su síntesis sobre el nihilismo europeo. En las siguientes líneas citadas, Nietzsche se hace y responde la pregunta del significado del nihilismo en el marco de su pensamiento: «9 [35] Nihilismo: falta la meta; falta la respuesta al «ipor qué?» ¿qué significa el nihilismo? - que los valores supremos se desvalorizan.» (Nietzsche, FP. Vol IV, [1887], 2007, 9 [35], p. 241).

El nihilismo aparece señalado como la desvalorización de los valores supremos, aquellos que fundamentaban una forma concreta de concebir el mundo y la vida en la sociedad europea; o lo que es lo mismo, la desaparición tanto del fundamento como del telos de la vida, tanto de la base como del porqué de la existencia.

Tres preguntas fundamentales surgen a raíz de esta definición: ¿cuáles son esos valores supremos europeos desvalorizados, según Nietzsche? ¿Cómo se ha producido esa desvalorización? ¿Por qué la desvalorización nos lleva al nihilismo?

Para responder a la primera pregunta, tenemos a un fragmento póstumo donde Nietzsche condensa una breve crítica sobre las ventajas de creer en la doctrina moral cristiana. Esta moral aportaba los siguientes elementos al sujeto: un valor absoluto frente a la contingencia del resto de los seres vivos, un sentido total de la realidad como existencia perfecta, y una sabiduría trascendente «acerca de esos valores absolutos y le daba así un conocimiento adecuado precisamente para lo más importante» (Nietzsche, FP. Vol IV, [1886-1887], 2007, 5 [71], p. 164). De esto se deducen tres valores supremos de carácter cristiano: la identidad absoluta del ser humano forjado a imagen y semejanza de Dios, el sentido y la perfección del mundo fruto de la 
omnipotencia divina, y el conocimiento humano trascendente sobre la verdad de estas cosas. Todos estos valores subyacen a un último valor supremo: la idea de Dios.

Además de estos valores cristianos, Franco Volpi en su obra El nihilismo, comenta el fragmento póstumo Crítica del Nihilismo (Nietzsche, FP. Vol IV, [1887-1888], 2007, 11 [99], p. 394-395), donde encontramos un análisis de tres categorías metafísicas que definen valores supremos de la cultura europea. En primer lugar, estaría el sentido de la existencia, aquel fin que justifica la realidad del devenir; luego encontraríamos la unidad, el principio organizador y unificador del devenir enlazado al fin ya aportado; y por último estaría la verdad, una categoría que permite el conocimiento de las anteriores. (Volpi, 2004, p. 63-64). Dado que existe una relación intrínseca entre estas dos series de valores, metafísicos y cristianos, Volpi ofrece, además de una referencia a la definición del nihilismo que ya hemos comentado, un esquema de tres valores supremos donde se resumen ambos listados.

«El nihilismo es, por lo tanto, la "falta de sentido" que aparece cuando se debilita la fuerza vinculante de las respuestas tradicionales al "¿para qué?" de la vida y del ser, y esto sucede a lo largo del proceso histórico, en el curso del cual los supremos valores tradicionales que daban respuesta a aquel "ipara qué?" -Dios, la Verdad, el Bien- pierden su valor y perecen, generando la condición de "insensatez" en la que se encuentra la humanidad contemporánea.» (Volpi, 2004, p. 59)

Podemos considerar como elenco de valores supremos referidos por Nietzsche los aquí resumidos por Volpi. Dios es sin duda el fundamento de los valores cristianos citados anteriormente, la verdad y su búsqueda es un valor supremo que se puede rastrear no solo en el conocimiento humano trascendente de la religión cristiana, sino además en la búsqueda del sentido del mundo presente en la labor metafísica. Por último, el bien es la aportación moral de tales doctrinas a la cultura europea. Una definición sobre lo bueno y lo malo con sus respectivas estimaciones de valor.

Para responder a la segunda pregunta sobre cómo se produce la desvalorización de estos valores supremos, podemos acudir un pasaje del Crepúsculo de los ídolos denominado Historia de 
un error. Un texto que expone el desarrollo de la historia de la metafísica en seis pasos, que comienza con el platonismo y finaliza con el nihilismo. (Nietzsche, CI, [1888], 2005, p. 57-58)

En la primera etapa Nietzsche nos presenta la doctrina platónica, un pensamiento que sitúa la verdad y el bien en un mundo ajeno a la realidad sensible, el cual es accesible a través del conocimiento. En la segunda etapa la doctrina platónica se transforma en doctrina cristiana y antepone el factor de la compasión al conocimiento, elevando el mundo ideal platónico a una segunda vida a través de su idea de paraíso. Estos dos momentos componen la germinación del nihilismo en la cultura europea. En el primero se establecen un sentido del mundo basado en una división ontológica: una realidad sensible y una realidad ideal consideradas respectivamente "mundo aparente" y "mundo verdadero". Tal sentido conlleva una serie de estimaciones morales. En el segundo momento este sentido se extiende a toda la cultura europea a través de la religión y se vuelve inalcanzable en vida, se requiere de la compasión constante y de la muerte para poder llegar a la verdad.

En la tercera etapa surge una variante de la moral cristiana que permite al mundo verdadero imponer deberes a los actos humanos del mundo sensible. Es la referencia a la moral imperativa y categórica de Kant. En la cuarta etapa comienza el cambio, emerge el conocimiento positivista, la ciencia moderna fraguada en la experiencia que se encierra en el conocimiento del mundo sensible y desestima toda reflexión sobre lo inteligible. Estas dos etapas podrían definirse como el cambio de tendencia: primero encontramos el mayor discurso del "mundo verdadero", y segundo encontramos una nueva forma de conocimiento que se rebela ante él centrándose en el "mundo aparente”. El momento en el que la búsqueda de la verdad se vuelve contra su propia moral.

En la quinta etapa este conocimiento empírico ha eliminado el "mundo verdadero". Es entonces cuando en la sexta etapa este proceso supone un verdadero problema. Dada la reciente desaparición del mundo verdadero de lo inteligible, que a la vez es el paraíso cristiano, encontramos 
que la realidad se limita a ese desprestigiado y odiado mundo sensible. Al ser humano no le queda ningún mundo que apreciar. El sentimiento de rechazo ante la realidad por este proceso es el denominado nihilismo, un pathos Nietzsche define con las siguientes palabras: «Un nihilista es el hombre que, respecto del mundo tal como es, juzga que no debería ser, y, respecto del mundo tal como debería ser, juzga que no existe.» (Nietzsche, FP. IV, [1887] 2007, 9[60], p. 250).

En las respuestas a esas tres dudas sobre surgidas de la definición del diagnóstico de Nietzsche, podemos señalar además la respuesta la pregunta más importante, aquella sobre el por qué la desvalorización nos lleva al nihilismo. Y esa respuesta es precisamente la conclusión final de todo el proceso: concebir la realidad como desprestigiada a través de otra superior, para luego descubrir que esa otra realidad no existe, lo que implica resignarse a una dimensión considerada en sí detestable. Ese es el sentimiento nihilista que describe el diagnóstico del nihilismo, el fruto del proceso histórico de la desvalorización.

Como hemos visto en este apartado, Nietzsche realiza una crítica a la metafísica y una crítica al cristianismo y a la moral para fundamentar su diagnóstico del nihilismo. En los siguientes apartados se desea ampliar el contenido de ambas críticas.

\subsection{Egepticismo: el germen nihilista inmerso en la metafísica europea}

La profesora Ávila Crespo, en su obra Lecciones de metafísica, expone que el pensamiento de Nietzsche puede entenderse como respuesta a la filosofía de Schopenhauer. (Ávila, 2012, p. 181) Nietzsche se aproxima al pensamiento metafísico de la filosofía occidental, pero lo entiende de forma pesimista. Si Schopenhauer es el actual culmen de la metafísica, entonces se trata de una disciplina funesta para la vida, dado que el filósofo romántico considera que los momentos más duros de la vida, como son el sufrimiento de enfermedades, la experimentación del dolor y la cercanía a la muerte nos acercan al pensamiento metafísico (Ávila, 2005, p. 168). 
En Más allá del bien y del mal encontramos un aforismo en el capítulo De los prejuicios de los filósofos, donde comienza una descripción nietzscheana sobre el pensamiento metafísico. La reflexión es idéntica a las primeras líneas de la obra Humano, demasiado humano, en el capítulo De las primeras y las últimas cosas. En ambos casos denuncia al pensamiento metafísico por su marcada división de la realidad en esencias y cosas sensibles, un resultado alcanzado a través de la búsqueda del origen y la entidad verdadera de las cosas.

\begin{abstract}
"[...] las cosas de valor sumo es preciso que tengan otro origen, un origen propio, - ¡no son derivables de este mundo pasajero, seductor, engañador, mezquino, de esta confusión de delirio y deseo! Antes bien, en el seno del ser, en lo no pasajero, en el Dios oculto, en la "cosa en sí" - ¡ahí es donde tiene que estar su fundamento, y en ninguna otra parte!» - Este modo de juzgar constituye el prejuicio típico por el cual resultan reconocibles los metafísicos de todos los tiempos; esta especie de valoraciones se encuentra en el trasfondo de todos sus procedimientos lógicos; partiendo de este «creer» suyo se esfuerzan por obtener su «saber», algo que al final es bautizado solemnemente con el nombre de «la verdad»." (Nietzsche, MBM, 2007, p. 23)
\end{abstract}

Esta reflexión continúa en Humano, demasiado humano hasta llegar a defender que esa búsqueda de las esencias es idéntica a la ensoñación de un «segundo mundo real». Nietzsche está exponiendo de esta manera el dualismo ontológico como propio de la metafísica, pero además está evidenciando la estimación de valor que conlleva: una relación de desprecio y aprecio por el mundo fáctico y sensible y por el mundo hipostasiado e inteligible, respectivamente. En resumen, el mundo cambiante de lo sensible se considera falso y aparente, mientras que el mundo esencial teorizado a través del discurso metafísico es ideal y verdadero. Se deduce de esta práctica no sólo un amor a la eternidad, sino también un odio al devenir. Y este pensamiento de amor-odio es lo que Nietzsche denomina con el nombre de "egepticismo", haciendo referencia a un deseo de momificación por parte de los metafísicos, un anhelo de transformación de lo cambiante en inmutable, un cariño por el hieratismo. Así aparece en el Crepúsculo de los ídolos: 
«¿Me pregunta usted qué cosas son idiosincrasia en los filósofos?... Por ejemplo, su falta de sentido histórico, su odio a la noción misma de devenir, su egepticismo". Los filósofos creen otorgar un honor a una cosa cuando la deshistorizan, sub specie aeterni [desde la perspectiva de lo eterno], - cuando hacen de ella una momia. Todo lo que los filósofos han venido manejando desde hace milenios fueron momias conceptuales; de sus manos no salió vivo nada real. Matan, rellenan de paja, esos señores idólatras de los conceptos, cuando adoran, se vuelven mortalmente peligrosos para todo, cuando adoran. La muerte, el cambio, la vejez, así como la procreación y el crecimiento son para ellos objeciones, - incluso refutaciones. Lo que es no deviene; lo que deviene no es... Ahora bien, todos ellos creen, incluso con desesperación, en lo que es.» (Nietzsche, $C I, 2002$, p. 51)

Si la vida cotidiana del ser humano se encuentra circunscrita precisamente a ese mundo que deviene constantemente, entonces el conocimiento metafísico establece un rechazo a la vida humana. Por ello Ávila Crespo dice haciendo referencia al pensamiento nietzscheano: “«Todavía parece alentar en la metafísica aquel «espíritu de la pesadez» que Nietzsche determinó con los adjetivos «serio, grave, profundo, solemne» y que no se aviene ya con tiempos como éstos.” (Ávila, 2005, p. 22-23).

En el aforismo "Crítica de la razón filosófica”, Nietzsche define su postura sobre ese arte de interpretar el sentido del mundo. Destaca que no hay forma de demostrar la existencia del mundo inteligible, en concreto menciona que los «signos distintivos que han sido asignados al «ser verdadero» de las cosas son los signos distintivos del no-ser, de la nada, - poniéndolo en contradicción con el mundo real es como se ha construido el «mundo verdadero»:» (Nietzsche, $C I$, 2002, p. 56-57). Dado que el mundo verdadero ha sido refutado y solo es aquello que deviene, los rasgos definidores del "ser verdadero" son los rasgos de la nada. Entonces la metafísica ha sido una fabulación del mundo a través de un sentido que empequeñece la vida, y por ello estima que es una forma de pensamiento decadente.

Sin embargo y para concluir, se evidencia que la metafísica no es decadente en sí, sino en debido a su egepticismo, ese componente cuyo desarrollo a lo largo de la historia ha producido el nihilismo. Con este componente la metafísica provoca el sentimiento: considerar que la vida experimentada tiene valor nulo por ser denominada de falsa y aparente ante otra realidad, 
considerada verdadera y por tanto de valor máximo. Nietzsche sitúa el inicio del egepticismo en el pensamiento platónico, y considera que desde entonces los diversos autores metafísicos han extendido diversos discursos que simplemente desarrollan este planteamiento inicial: pasando por Aristóteles, el pensamiento teológico medieval y el pensamiento metafísico moderno hasta llegar a Schopenhauer, donde se culmina esa doctrina de la decadencia vital.

\subsection{El nihilismo como fruto de la doctrina moral cristiana}

Otro de los factores fundamentales que conllevan la aparición del nihilismo en la cultura europea es el pensamiento moral cristiano. Ya hemos hecho alguna alusión a esta cuestión que aquí se aborda con mayor profundidad. Además de que el cristianismo es una de las fuentes generadoras de los valores supremos occidentales, los diferentes discursos metafísicos han estado en sintonía con la doctrina moral cristiana, inculcando su trasfondo religioso a la cultura europea a lo largo de la historia.

\footnotetext{
"En la gran fatalidad del cristianismo Platón es aquella ambigüedad y fascinación llamada el «ideal», que hizo posible a las naturalezas más nobles de la Antigüedad el malentenderse a sí mismas y el poner el pie en el puente que llevaba hacia la «cruz»... ¡Y cuánto Platón continúa habiendo en el concepto «Iglesia», en la organización, en el sistema, en la praxis de la Iglesia!" (Nietzsche, CI, [1888], 2002, 139)
}

Johann Figl ha destacado recientemente que la filosofía de Nietzsche está influenciada por el método comparativo de Max Müller para el estudio científico de las religiones a través de la lingüística, y por ello utiliza una especie de «hermenéutica transcultural», cuyos resultados definen los elementos fundamentales de las doctrinas religiosas. Esa metodología es una genealogía histórica fruto de ciencia filológica, filosofía y estudios comparativos, donde se consiguen individuar las ideas que subyacen a sus discursos doctrinales, y los resultados son hallados en sus obras. (Figl, 2014, p. 127-128). De esta manera Nietzsche destaca que frente a la religión clásica griega, tanto el cristianismo como el budismo son religiones nihilistas. 
En relación precisamente al método científico Nietzsche entiende no solo un estudio, sino también un propósito. El conocimiento científico de la religión, y la ciencia moderna en general, deben constatar la refutación de las verdades religiosas. Así a comienzos de su labor universitaria, en un fragmento personal publicado póstumamente, Nietzsche escribe: «Todos los dioses deben morir»: es la antigua idea alemana de que la ciencia sigue todavía penetrando con una gran fuerza hasta lo más hondo.» (Nietzsche, FP. Vol I, [1871], 2010, 5 [57], p. 126.)

Con esa intención en el marco de su pensamiento realiza una crítica de la religión, concluyendo que en su seno también se encuentra el origen del nihilismo europeo.

Gran parte de esa «hermenéutica transcultural» nietzscheana se encuentra en la obra $L a$ genealogía de la moral, donde Nietzsche expone algunas tesis sobre la moral cristiana. A través de una comparación etimológica, destaca cómo aquellas palabras relacionadas con el concepto actual noble estaban relacionadas en su origen con el concepto moral bueno. (Nietzsche, GM, 1996, p. 33 34). Por ello a través de la lengua Nietzsche supone que, en los albores de la civilización, el concepto "bueno" se ha asociado siempre a la altitud en una sociedad jerárquica, mientras que "malo" sería exactamente su opuesto. Nietzsche asoció esta moral a Roma, y quizás intentaba referenciar a la sociedad romana donde se admiraba al cónsul republicano, aquél que había realizado el famoso cursus honorum de méritos que finalizaba con la ostentación del poder político, económico y militar.

Sin embargo, ante esta moral se presenta su antónimo: la doctrina cristiana. Aquella forma de pensar que asocia el concepto bueno a la pobreza y a la inferioridad, y la maldad al uso de poder. Debido al surgimiento del cristianismo en la sociedad romana de la antigüedad, Nietzsche expone que se produce un conflicto entre esas dos jerarquías morales. Este podría ser entendido como la pugna que estableció la expansión del judeocristianismo en el territorio romano hasta ser reconocida 
como la religión dominante de todo el imperio latino en el siglo IV d. C. Así lo expone el propio autor:

«Concluyamos. Los dos valores contrapuestos «bueno y malo», «bueno y malvado», han sostenido en la tierra una lucha terrible, que ha durado milenios; y aunque es muy cierto que el segundo valor hace mucho tiempo que ha prevalecido, no faltan, sin embargo, tampoco ahora lugares en los que se continúa librando esa lucha, no decidida aún. [...] El símbolo de esa lucha, escrito en caracteres que han permanecido hasta ahora legibles a lo largo de la historia entera de la humanidad, dice «Roma contra Judea, Judea contra Roma»:» (Nietzsche, GM, 1996, p. 58-59)

En el último tratado de La genealogía de la moral Nietzsche trabaja otro de los aspectos propios de la moral cristiana: sus ideales ascéticos. Gracias a su método consigue denominar cuáles son sus principios: la pobreza, la humildad y la castidad. Con ese conocimiento concluye que la doctrina moral cristiana establece una defensa virtuosa de los ideales ascéticos que influenciaron la cultura europea. El establecimiento o victoria del cristianismo es en las líneas de esa obra, una moral religiosa reactiva a aquella moral afianzada en el poder. El establecimiento del cristianismo en Europa no fue una cuestión ética, sino histórica y fruto de una serie de condicionantes. Se impuso en un momento determinado, favorable, y desde entonces según Nietzsche continuaba haciéndolo. «Pero aquella espiritualidad lo hizo, justamente en cuanto era el instinto dominante que imponía sus exigencias a todos los demás instintos -y lo continúa haciendo; si no lo hiciera, no dominaría, en efecto. Nada pues, hay aquí de «virtud».» (Nietzsche, GM, 1996, p. 126).

De esta manera el matiz "virtuoso" afincado en los conceptos bueno y malo, y relacionado con los ideales ascéticos, queda para Nietzsche relativizado, y por tanto también refutado. Guarda relación esta cuestión con un aforismo de la obra Humano, demasiado humano, que precisamente Nietzsche cita en la introducción a La genealogía de la moral como preámbulo de dicho estudio, y donde establece que la moral entendida cómo la jerarquía sobre lo bueno o lo malo, cambia según las civilizaciones. Luego todo establecimiento de moral es de índole relativo. (Nietzsche, $H D H$, 2001, p. 42). Nietzsche además en el capítulo La vida religiosa, expone a la persona ascética como 
seguidora de unos principios que promueven un rechazo a la vida. (Nietzsche, $H D H, 2001$, p. 113)

Por esta razón Nietzsche concluye al final de La genealogía de la moral, que los ideales ascéticos promovidos por el cristianismo son un tipo de moral impuesta a través de cuestiones históricas, cuya influencia perjudica la vida humana. Redefine al seguidor de la moral cristiana como seguidor de una "moral enferma". Evidencia que sus ideales ascéticos implican rechazar los recursos necesarios para la consecución de la vida, al eliminar los impulsos humanos del deseo y el querer. En suma, si los valores supremos de la moral cristiana se establecieron en la cultura europea de forma circunstancial, si su jerarquía moral de bueno y malo y sus ideales ascéticos son una valoración de la debilidad y un desprestigio de la capacidad, promoviendo una vida casi sesgada o nula; entonces la religión cristiana se dedica a una depauperación de la vida. Para terminar Nietzsche destaca un sentimiento adicional en dicha creencia: la compasión, una admiración por alguien más débil que uno mismo, considerar al más desdichado como el mejor. Con estos componentes el cristianismo presenta una dinámica de destrucción personal constante cuyo resultado es una decadencia de lo vital. Es un proceso ajeno al descrito anteriormente con la metafísica pero que conlleva un resultado común, el desprestigio de la vida terrenal, una forma de pensamiento que provoca el freno de toda acción, el deseo de no desear absolutamente nada, o lo que es lo mismo, el pathos nihilista. (Nietzsche, GM, 1996, p. 141-142).

Podemos concluir este apartado citando la obra el Crepúsculo de los ídolos, donde Nietzsche reafirma esta tesis. Allí expone que el ascetismo elimina las pasiones humanas, consideradas para él las verdaderas raíces de la vida. Luego va en contra de las bases de la vida.

«La Iglesia combate la pasión con la extirpación, en todos los sentidos de la palabra: su medicina, su «cura», es el castradismo. No pregunta jamás: «¿cómo espiritualizar, embellecer, divinizar un apetito?» - en todo tiempo ella ha cargado el acento de la disciplina sobre el exterminio (de la sensualidad, del orgullo, del ansia de dominio, del ansia de posesión, del ansia de venganza). - Pero atacar las pasiones en su raíz significa atacar la vida en su raíz: la praxis de la Iglesia es hostil a la vida...» (Nietzsche, GM [1888], 2005, p. 60) 


\subsection{Tipología y superación del nihilismo en Nietzsche}

En los Fragmentos Póstumos que abarcan los años 1885 y 1889, Friedrich Nietzsche ofrece sus últimas declaraciones sobre el nihilismo, y probablemente a través de tales fragmentos puede establecerse una tipología de diferentes nihilismos, denominados a través de sus adjetivos y características. Nietzsche destaca entre ellos el nihilismo perfecto, también llamado consumado o completo, e indica haber desarrollado una superación del propio problema cultural y axiológico, es decir, se evidencia como la solución, un nihilismo terapéutico. En este apartado se intentará exponer precisamente un esquema general de los mismos.

En primer lugar, convendría aclarar la evidente relación que presentan el nihilismo con el pensamiento pesimista. Nietzsche apunta que el pesimismo es un «preliminar» o un «preludio» del nihilismo, luego podemos entenderlo como algo que viene exactamente antes del nihilismo, pero que no es nihilismo en sí. El pensamiento nihilista precede al pesimista, pero no son el mismo modo de pensar. (Nietzsche, FP. Vol IV, [1887], 2007, 10 [58], p. 318.)

No obstante, ambos conceptos tienen una clara relación. El pesimismo va exactamente antes, su desarrollo tiene como consecuencia el florecimiento del nihilismo, al igual que el desarrollo de la verdad. Se entiende así el pesimismo como aquel sentimiento causado por el malestar del primer tipo de moral humana, que asociaba los conceptos bueno y malo a poder y ausencia de poder. Por tanto, es el impulso de la inversión de valores propugnado por el cristianismo, que reinterpreta tales conceptos morales a los términos pobre y poderoso, respectivamente. Es el impulso de esa inversión moral. (Nietzsche, FP. Vol IV, 2007, [1887], 9 [107], p. 267-268.) En consecuencia, el pesimismo es uno de los factores que desencadenan directamente la pugna moral, e indirectamente el nihilismo europeo. Pesimismo y nihilismo no son el mismo pathos, pero poseen una relación interna. No obstante, se aclara que el pensamiento nihilista no tiene por qué ser pesimista. 
El primer nihilismo que debemos de definir en esta tipología es el filosófico, caracterizado por ser un inicio del sentimiento nihilista, o mejor dicho, un sentimiento nihilista aún incompleto. Si acudimos a su definición en los Fragmentos póstumos, descubrimos que sus características son previas a la definición general de nihilismo.

\begin{abstract}
«El nihilista filosófico está convencido de que todo acontecer carece de sentido y es en vano; y que no debería haber ningún ser carente de sentido y en vano. Pero ¿de dónde procede este: no debería? [..] El nihilista opina en el fondo que la mirada sobre semejante ser yermo e inútil actúa sobre un filósofo volviéndolo insatisfecho, yermo, desesperado [..] Ello conduce a la absurda valoración siguiente: el carácter de la existencia tendría que complacer al filósofo si ésta debe subsistir con alguna justificación...» (Nietzsche, [18871888], 2007, p. 394)
\end{abstract}

Teniendo en cuenta que Nietzsche describe muchas veces la filosofía como una forma de suponer lo que acontecerá, de hecho él mismo subtitula su obra Más allá del bien y del mal con la frase Preludio de una filosofía del futuro, podríamos decir que el nihilismo filosófico es previo a su definición general. Pero en verdad se trata de cómo, a través de la filosofía, se anticipa el establecimiento propio del nihilismo. Sus características coinciden, curiosamente, con el cuarto estadio de la Historia de un error encontrada en el Crepúsculo de los ídolos. Y asociado a esta referencia podemos decir que el nihilismo filosófico se encuentra antes del nihilismo como tal, que de hecho es el sexto estadio. Por otro lado, aunque antes hemos categorizado el pesimismo como un agente desarrollador del nihilismo, en el relato Historia de un error se hace referencia a la búsqueda de la verdad como otro de sus desencadenantes, y ello estaría mucho más relacionado con este nihilismo filosófico.

La definición general de nihilismo que deseamos exponer es aquella que Nietzsche define como un «estado patológico intermedio». El sentido de "intermedio" parece referir a la idea de que los valores desvalorizados aún no han sido totalmente desechados, es decir destruidos, y por ello al mismo tiempo no es necesario nuevos remedios, sentidos, o valores para superar su ausencia. Están desvalorizados, pero no desaparecidos. (Nietzsche, FP. Vol IV, [1887], 2007, 9 [35], p. 242). Hemos 
de relacionar esta idea precisamente con la muerte de Dios explicitada en las líneas de El loco de $L a$ gaya ciencia, donde el personaje anuncia a la sociedad que el hombre ha matado a Dios, pero que aún es demasiado pronto para que la sociedad asuma todas las consecuencias del hecho. En otras líneas del mismo libro comenta: «Dios ha muerto, pero los hombres son de tal condición que habrá tal vez durante miles de años cavernas donde se enseñe su sombra.» (Nietzsche, GC, [1883], 1985, p. 981) En el contenido de este aforismo entendemos que Dios, el mayor de todos los valores supremos, cae produciendo la desvaloración de la cultura europea, sin embargo la propia Europa aún no se hace eco de este proceso. Esa es la razón de que este nihilismo sea denominado como "intermedio", en sentido de inacabado, no superado, no consumado. Es el estado con el que Nietzsche describe a su sociedad contemporánea.

Existen dos tipos de nihilismo que van más allá de esa forma general e intermedia. Si seguimos las consecuencias lógicas de la desvalorización de los valores supremos, podemos alcanzar dos tipos de sentimientos: el sentimiento de fuerza o el sentimiento de debilidad. Su desarrollo conlleva la aparición del nihilismo activo y el nihilismo pasivo. El primer caso, fruto del desarrollo de la fuerza, consiste en la destrucción total de los valores supremos e intenta superar la necesidad de establecimiento de valores y nuevas interpretaciones, una necesidad que Nietzsche considera totalmente humana e insuperable. En el segundo caso, fruto del desarrollo de la debilidad como fuerza opuesta, los valores son totalmente rechazados pero el individuo además deja de considerar cualquier interpretación valorativa como adecuada, de manera que es capaz incluso de oponerse a tales discursos. Ambos casos llegan a un mismo resultado, van más allá del nihilismo intermedio, pero siguen siendo formas incompletas. (Nietzsche, FP. Vol IV, [1887], 2007, 9 [35], p. 241-242.)

A la hora de hablar del nihilismo activo hemos mencionado una cuestión que merece mayor referencia: se trata de la necesidad humana de aportar una interpretación de sentido a la vida y a la 
existencia. Esta idea se encuentra también en la literatura nihilista rusa de finales del siglo XIX, de la cual el propio Nietzsche se nutre. Para corroborar esto podemos referirnos a la obra de Turgueniev, Padres e hijos, donde uno de los coprotagonistas, Bazarov, se declara abiertamente nihilista. El personaje se define como alguien que no cree en nada, y que solo se apoya en los hechos estudiados científicamente. Sin embargo, a lo largo del desarrollo de la novela el personaje se enfrenta a preguntas de mayor calado sobre el sentido de la existencia, y así acaba declarando que «La Naturaleza no es un templo, sino un taller, y el hombre, su obrero.» (Turgueniev, 1960, p. 921) Tal forma de entender la realidad puede ser breve y simple, pero es un sentido de la misma, que parte desde su perspectiva positivista y científica. Es alguien que no cree en nada, y sin embargo cree en la ciencia. Incluso desde un punto de vista extremadamente científico sigue existiendo la necesidad de aportar un sentido a toda la realidad. Ante esta idea se evidencia el nihilismo como problema, su establecimiento no puede ser el final, en algún momento el sujeto humano necesitará nuevos valores y nuevos sentidos.

Regresando a la tipología, podemos recapitular que todos los nihilismos mencionados hasta ahora han sido formas incompletas del mismo. El sentido de "incompleto" parece estar referido a aquellos estadios que aún no han superado el problema, y de esto se deduce que superar el nihilismo significa completarlo. Ahora bien, si todos los nihilismos incompletos coinciden en un factor, sufrir la desvalorización de los valores no desechados, entonces un nihilismo completo se define precisamente por llevar a cabo una transvaloración de todos los valores. (Nietzsche, FP. Vol. IV, [1887], 2007, 10 [42], p. 310.) El sentido del concepto transvaloración implica desvalorización, superación de los valores, y establecimiento de nuevos valores.

Así nos adentramos ahora en otros tipos de nihilismos. El primero, denominado radical, va más allá de los casos anteriores comentados e inicia la superación del problema, pese a ser todavía incompleto. El segundo, denominado extremo, si termina la superación, consuma o completa el 
nihilismo.

Las características del nihilismo radical son muy parecidas al nihilismo activo. Se trata de un pensamiento con una fuerza que refuta el establecimiento de los valores supremos e impide el desarrollo de nuevos valores. En el caso del nihilismo activo, el signo de fuerza era incapaz de desarrollar nuevos valores; su diferencia con el nihilismo radical es la Antinomia. «Ésta es la antinomia: en cuanto creemos en la moral, condenamos la existencia.» (Nietzsche, 2007, [1887], 10 [192], p. 363.) Ese pensamiento impide establecer una nueva moral divina, por ello este modo radical ejerce un nuevo tipo de fuerza que, en lugar de ser incapaz de desarrollar, frena cualquier posible desarrollo. Por ello a este tipo de nihilismo se le asocia el concepto de "moral encarnada": el descubrimiento de que la moral divina tiene un origen terrenal, un origen humano que índica la imposibilidad de cualquier moral no-secular.

Con el nihilismo extremo abordamos finalmente la terapia contra el problema. Se trata de un ir más allá del nihilismo filosófico, normal, activo, pasivo y radical. Partiendo de este último, se añaden nuevos valores que permiten aportar un nuevo sentido a la realidad del devenir. Este nuevo sentido, de postulado ateleológico para evitar la creación de "segundos mundos", acepta como divino el cambio constante del devenir que tiene principio y carece de fin. Esto obliga a la existencia a alcanzar mediante cambios, tarde o temprano su punto de partida. Una existencia que regresa eternamente a su punto de inicio.

«Pensemos este pensamiento en su forma más terrible: la existencia, tal como es, sin sentido y sin meta, pero retomando inevitablemente, sin un finale en la nada: «el eterno retomo».

Ésta es la forma más extrema de nihilismo: ¡la nada (lo «carente de sentido») eternamente!» (Nietzsche, 2007, [1887], 5 [71], p. 161.)

Por tanto el nihilismo extremo incorpora nuevos elementos al nihilismo radical, en este caso añadiendo la hipótesis del eterno retorno, la cual es defendida como un perspectivismo, dado que a 
partir del nihilismo toda verdad o todo «tener-por-verdadero», se descubre para Nietzsche como falso. No obstante el nihilismo extremo no se detiene ahí, Nietzsche lo concibe como una forma divina de pensar el devenir, de idealizar aquellos elementos de la realidad que habían sido desvalorizados, desprestigiados; le es «infiel» a los valores supremos que ya ha destruido, dado que no solo los ha eliminado, sino que los ha sustituido por nuevos valores. (Nietzsche, FP. Vol. IV, [1887], 2007, 10 [43], p. 310.) La capacidad de la voluntad de poder se presenta plena en esta forma del nihilismo, y la persona puede pensar desde un nuevo mundo metafísico que no desarrolla un nuevo germen nihilista, luego se restringe a una interpretación a-teleológica que enfoca su aprecio y valor en la realidad sensible, inmediata, devenida, aquella de la cual tenemos evidente constancia empírica. En suma, que ame lo hechos cambiantes de la realidad. Este es el sentido del concepto nietzscheano amor fati, el cual, según comenta Luís Jiménez Moreno, consiste en defender la grandeza de toda la realidad y de nuestra existencia desde la propia perspectiva del ser humano. (Jiménez, 1986, p. 120.) Un sí a la vida humana y a la realidad del devenir que no necesita ser valorizada desde ninguna otra existencia. Es por tanto el auténtico nihilismo completo y perfecto.

En conclusión, gracias esta tipología podemos identificar qué elementos nos llevan hasta el nihilismo extremo o perfecto, el cual es una superación de la problemática del nihilismo europeo diagnosticada por Nietzsche. Así el nihilista radical, gracias a la voluntad de poder, desarrolla sin fin una serie de ficciones metafísicas, diferentes perspectivas sobre el sentido del mundo y su propia existencia, siempre en el marco de los conceptos eterno retorno y amor fati. Nietzsche ofrece una terapia que sigue este camino, cuyo método consiste en seguir las consecuencias lógicas de todas las modalidades nihilistas hasta el final. Desde el pesimismo y la búsqueda de la verdad propia del nihilismo filosófico, para llegar a la verdadera manifestación del nihilismo, ese estado intermedio del cual avanzamos hacia sus variables activa y pasiva. De ahí podemos continuar hacia el nihilismo radical, donde se desechan todos los valores supremos; y finalmente llegar al nihilismo extremo 
donde se desarrollan los nuevos valores. El último estado de la terapia.

\subsection{El nihilismo como análisis axio-antropológico de la cultura occidental}

A través de estos apartados hemos intentado exponer una panorámica de los aspectos generales que componen el diagnóstico del nihilismo europeo según Nietzsche. Sin embargo y como conclusión a todo lo dicho, nos queda destacar que este problema no parece completamente metafísico o religioso; en concreto, es posible que se trate de una cuestión de valores culturales. De hecho, Jiménez Moreno, en referencia al diagnóstico del nihilismo dentro de la filosofía de Nietzsche, destaca que es un fenómeno axiológico y antropológico, está centrado en los valores culturales del ser humano occidental.

«Nietzsche alude, por todas sus referencias, a una especie de nihilismo axiológicoantropológico, que se ha implantado en la sociedad europea y occidental, como un proceso de alienación desde que la conceptualización, la logicización de los conocimientos y valoraciones han ido suplantando la atención debida a la vida misma, al sentir y a un modo de realizarse.» (Jiménez, 1986, p. 159)

Discutir sobre el problema del nihilismo, poner en valor el diagnóstico y ofrecer actualizaciones y nuevas soluciones a la cuestión, es un debate que entronca aspectos metafísicos, científicos y religiosos; pero principalmente se centra en cómo tales ámbitos del ser humano influencian una cultura, y por ende toda una sociedad. El núcleo del diagnóstico es, en resumen, el pathos decadente provocado por esos valores culturales de Occidente que han sido desvalorizados y que necesitan ser superados. Por supuesto, toda nueva forma de valores sería el fruto de nuevas interpretaciones metafísicas, científicas y religiosas sobre la realidad. Esto es lo que precisamente Keiji Nishitani va a ofrecer desde sus obras The Self-Overcoming of Nihilism y La religión y la nada: una nueva interpretación metafísica y religiosa que intenta superar el problema nietzscheano, sin caer en las críticas metafísicas, morales y religiosas que establece Nietzsche. El objetivo de la 
superación del nihilismo en Nishitani será dar un nuevo sentido a la realidad que no esconda aspectos nihilistas y pueda ser aceptado por puntos de vista filosóficos, metafísicos, científicos, religiosos y cotidianos.

\section{La recepción del nihilismo europeo nietzscheano en la filosofía de Keiji Nishitani}

\subsection{Nishitani y su relación vital con el nihilismo europeo de Nietzsche}

Las reflexiones de Keiji Nishitani sobre el problema y la superación del nihilismo europeo tienen dos perspectivas: una personal y otra filosófica. Podemos adelantar ya que lo personal, lo subjetivo, y la reflexión que afecta de la existencia del sujeto es fundamental en su filosofía. Por ello aunque presenta rasgos religiosos, debería ser caracterizada como existencialista, preocupada por la existencia del sujeto humano en el mundo. En el caso del nihilismo de Nietzsche, lo personal y existencial se inmiscuye al considerar haber padecido los síntomas del problema incluso antes del conocimiento del diagnóstico, o mejor dicho antes de su inmersión en la filosofía. Con el descubrimiento de la filosofía nietzscheana, Nishitani aborda la cuestión como una preocupación profesional pero sobre todo como una cuestión vital.

Algunas muestras de este aspecto son aportadas por James W. Heisig, al comentarnos en un breve apartado sobre la vida y carrera de Nishitani, que ya en sus estudios de adolescente se interesó por las lecturas de Kitarō Nishida, Feodor Dostoievsky y Nietzsche. Podemos entender gracias a ello una vocación filosófica, pero sobre todo por Dostoievsky y Nietzsche podemos suponer un interés por el nihilismo. (Heisig, 2002, p. 233). La influencia temprana que Nietzsche dejó en Nishitani fue bastante importante, de hecho Graham Parkes en la introducción a The SelfOvercoming of Nihilism, comenta una importante expresión de Nishitani: «As a young man, I used to carry Thus Spoke Zarathustra around with me wherever I went-it was like my Bible.» (Parkes, 1990, p. xx). 
Debido a esto podemos decir que Keiji Nishitani padecía un pathos nihilista desde su juventud. Por eso precisamente Ueda Shizuteru nos reseña, en sus notas sobre la obra citada de Nishitani, unas líneas encontradas en otro texto suyo titulado My Phisophical Starting Point donde aclara: «"The fundamental task for me, before philosophy and through philosophy, has been, in short, the overcoming of nihilism through nihilism"» (Shizuteru, 1990, p. xxx.).

Superar el nihilismo a través de sí mismo y sin buscar otro camino, antes y durante su vida filosófica. Ese fue el objetivo vital de Keiji Nishitani. Heisig nos comenta que, seguramente, la razón de este problema personal con el nihilismo se basaba en una cuestión social y cultural propia de Japón a comienzos del siglo XX. Desde los inicios de la era Meiji a mediados del siglo XIX, el país nipón pasó por un proceso de aculturación occidental animado desde las instituciones del estado. Un anhelo de modernización debido al auge de las grandes revoluciones industriales de Occidente, y a la apertura del país a las relaciones extranjeras. Aquello significó un cambio de conciencia cultural, una superación del clásico concepto de etnocentrismo. La sociedad japonesa aceptó la siguiente premisa: cuanto menos japonesa y más occidental fuera, mayor modernización obtendría. Esta aculturación de Japón siguió desarrollándose hasta casi mediados del siglo XX. Debido a ello, la nueva generación de intelectuales nacidos a comienzos de dicho siglo presentaba una pérdida de identidad cultural, o también podríamos decir que sufrían una desvalorización de sus valores culturales debido a imposición de valores occidentales.

Según esto y si aceptamos el análisis cultural de Nietzsche, podríamos aventurar que la sociedad japonesa de comienzos del siglo XX estaba en riesgo de sufrir el problema del nihilismo dada su propia desvalorización cultural.

«Un motivo que en parte explicaría su atracción por el pensamiento nihilista, y que no hemos de pasar por alto, es cierto malestar general provocado por la pérdida de identidad de muchos intelectuales japoneses que se habían alejado del pueblo y de la «tierra natal de su cultura tradicional» para perderse en ideas occidentales. El «yo» llego a ser, como dice Nishitani, efímero. Durante los primeros años de la guerra, estaba convencido de que el 
japonés de a pie llevaba todavía en el corazón el espíritu tradicional de su pasado, que sólo debía despertarse nuevamente para el bien de la sociedad en general.» (Heisig, 2002, p. 243244)

Cuando Nishitani finalizó sus estudios en filosofía con una tesis sobre Schelling, marchó con una beca a Friburgo durante dos años para ser alumno de Martin Heidegger. Precisamente el contenido de aquellas clases fue el nihilismo de Nietzsche, un tema en el que Nishitani tenía cierta instrucción, y eso le permitió dar una conferencia sobre Nietzsche y Eckhart. El aprendizaje de aquellos cursos, su preparación previa en la materia del nihilismo, y el contenido de aquella conferencia forjaron su conocimiento sobre dicho problema en varios autores, pero centrado sobre todo en Nietzsche, y con una perspectiva filosófica propia. El resultado final fueron una serie de lecciones impartidas en un seminario de la Universidad de Kioto años después, cuyo contenido es la obra The Self Overcoming of Nihilism. En sus líneas Nishitani expone la filosofía nietzscheana como análisis y autosuperación del nihilismo, pero también trabaja problemas ulteriores nihilistas. Los nuevos matices de ese nihilismo contemporáneo le motivarán para desarrollar una nueva vía para superar el nihilismo en su trabajo La religión y la nada.

Respecto a su versión del nihilismo de Nietzsche, Parkes comenta que pese a haberlo estudiado con Heidegger, la interpretación de Nishitani es totalmente independiente de la interpretación heideggeriana. (Parkes, 1990, p. xxii). Nishitani entiende a Nietzsche como el socavamiento final de la metafísica hasta unas profundidades tan grandes que permite emerger el pathos nihilista, que este japonés denomina con la expresión "abismo de la nihilidad".

En la obra filosófica de Nishitani se puede apreciar que acepta tanto el diagnóstico del nihilismo de Nietzsche como la terapia que el propio autor ofrece. Para él esa idea implica leer a Nietzsche, comprenderlo, interpretarlo y aplicarlo como una praxis filosófica existencial que permite consumar el nihilismo. El texto The Self-Overcoming of Nihilism no es su primer trabajo, pero asienta las bases de su principal obra La religión y la nada. Esto se debe precisamente a que la 
superación del nihilismo que promueve Nishitani es para él la base de la indagación y de la creación filosófica. Heisig expone que Nishitani no inició su camino filosófico gracias una admiración por la existencia y a través de un deseo de saber, tal como propone Karl Jaspers, sino precisamente por colmar una necesidad, su propio nihilismo. «Hijo de su época, entendió que el único camino hacia la filosofía sería el que comenzara en una desesperación nihilista sobre la condición humana, [...]» (Heisig, 2002, p. 242). Esta idea puede ser también interpretada como el inicio de todo budista Zen en la reflexión filosófica, dado que esta doctrina promueve una duda completa sobre la existencia que llega a impregnar la condición del propio sujeto.

\subsection{Existenz. Metodología nietzscheana para una investigación del nihilismo}

Nishitani considera que el análisis nietzscheano de la filosofía, de la ciencia moderna, de la cultura y de la religión en Occidente, es una forma adecuada de investigación existencial capaz de revelar el problema nihilista de la sociedad europea. Por eso también es capaz de desarrollar una superación del problema. De esta manera encuentra en Nietzsche una metodología para la investigación del nihilismo, un procedimiento que permite extraer un diagnóstico de sus diferentes formas y componer sus equivalentes curas.

El texto The Self-Overcoming of Nihilism comienza identificando dos problemas en la investigación del nihilismo, y el primer problema de está directamente relacionado con lo dicho. Nishitani considera que las filosofías del siglo XX, en concreto los existencialismos, son formas de investigación sobre el nihilismo que no abordan ninguna cuestión desde el sujeto, y para él esa es la auténtica perspectiva existencial. En tales filosofías entiende una relación objetiva con la nihilidad lo que impide que impregne al ego humano, que él posteriormente define como una perspectiva de la conciencia. No hay en esos pensamientos una relación subjetiva con la nihilidad, con el pathos nihilista de lo "en vano". Para abordar esta cuestión correctamente, el pensamiento filosófico debe 
cuestionar la nihilidad hasta el punto de cuestionar al propio individuo. Para resolver el fundamento del nihilismo, hemos primero de resolver el fundamento de nosotros mismos. «But if nihilism is anything, it is first of all a problem of the self» (Nishitani, 1990, p. 1) El filósofo japonés expone: si un análisis puede llevarnos a la superación del nihilismo, entonces debe hacerlo tanto a través del nihilismo como a través del sujeto mismo. En ello fundamenta el significado del título "The SelfOvercoming of Nihilism": la autosuperación del nihilismo, desde el ego y desde el propio nihilismo. Por tanto, hay una relación intrínseca entre el nihilismo como problema y la existencia de quien lo padece. Hemos de entender el nihilismo como existencia.

Por esta razón Nishitani entiende que una filosofía como la de Nietzsche es una forma adecuada de tratar con la nihilidad, dado que en ella el nihilismo se entiende a través de su influencia sobre el individuo, y su autosuperación postula el nacimiento un nuevo ego (el Übermensch). Es una manera de descubrir el nihilismo en todas sus facetas y así poder autosuperarlo. Nishitani entiende además una relación intrínseca de la filosofía nietzscheana con el pensamiento budista, lo cual puede ser expuesto a través de Malcom David Eckel en su texto divulgativo sobre el budismo. Allí destaca que esta religión define el correcto conocimiento como prajnā, un término que tanto en la tradición Theravāda ${ }^{3}$ como en la tradición Mahāyāna $a^{4}$ implica entender la realidad como una nada, que acaba provocando al sujeto una duda existencial sin respuesta. (Eckel, 2004, p. 60-61). Si para Nishitani esa "nada budista" es un pensamiento cercano al "abismo de la nihilidad", entonces está estableciendo un paralelismo entre un rasgo principal del pensamiento nietzscheano y el pensamiento budista.

En general, Nishitani concibe la filosofía nietzscheana como una metodología de investigación cuyo objeto de estudio somos nosotros mismos, una forma de vivir en nosotros la

3 Rama del budismo. El término significa "Enseñanza de los Ancianos". Se caracteriza por el objetivo de llegar a ser ahrat, que quiere decir fiel seguidor de Buda. (Lanzaco, 2000, p. 244)

4 Rama del budismo. El término significa "Gran vehículo". Se caracteriza por el objetivo de llegar a ser Boddhisattva, directamente Buda. (Lanzaco, 2000, p. 244) 
reflexión filosófica; la investigación debe establecerse como un acto de introspección, de aislamiento, debe iniciar una separación del individuo con el devenir histórico que le rodea. Tenemos que filosofar como ermitaños, tal como comenta Nishitani aludiendo un fragmento póstumo de Nietzsche: «as a philosopher and a hermit by instinct, who finds his advantage in withdrawing to the side, in standing outside, in patience, in hesitation, in lagging behind;» (Nishitani, 1990, p. 30) Esta es la imagen del Zaratustra, el eremita que se separó para superar el nihilismo, y una vez resuelto descendió de las montañas a la civilización.

Ahora bien, aunque el procedimiento nos separa del curso de la historia, la introspección debe estar enfocada precisamente en el curso de la historia, desde su actualidad y teniendo en cuenta su pasado. Uno no indaga directamente sobre sí mismo o sobre el hecho de aislarse del mundo del devenir, sino sobre el mundo del devenir: su historia, sus cambios, sus influencias, y nuestra forma de entenderlo. Si añadimos a esto que esa indagación sobre la realidad debe ser una indagación sobre uno mismo, descubrimos que la introspección centrada en la historia debe entenderse como una vivencia de esta. Nishitani lo define como experimentar la historia en el propio individuo, como si nuestro ego fuera el laboratorio de la historia.

«It means reflecting not upon history as it is, but up where it is headed. It does not mean to observe the reality of history and its ideas objectively as historians or philosophers of history do, but to experiment with history within oneself. It is to experiment with the future tendencies and issues of history by making the self one's laboratory. » (Nishitani, 1990, p. 30)

Estas son las razones por las que Nishitani describe la metodología nietzscheana como una filosofía de la historia, entiendo la historia como algo que implica al ego. Una filosofía de la historia de corte existencial. Se trata de intentar vivir y experimentar el devenir de la historia en el propio individuo, reflexionar sobre el mundo teniendo en cuenta cómo nos afecta. Es una práctica que concibe el pasado, el presente, y el posible futuro de la historia como eventos de la existencia individual. De esa manera el proceso histórico del nihilismo se vive a través del individuo. Esta 
forma de investigar el nihilismo permite atraer al individuo su inminente final lógico, lo que permite anticipar una superación. Esta última idea está relacionada con una sentencia concreta de Nietzsche escrita en sus Fragmentos Póstumos: «Esto que cuento la historia de los dos próximos siglos...» (Nietzsche, FP. Vol IV, 2008 [1887-1888], 11 [119], p. 400-401). En resumen, Nishitani define esta praxis como una metodología nietzscheana, denominada con el término Existenz. (Nishitani, 1990, p. 31).

En conclusión, la Existenz nietzscheana es un método que permite analizar y auto-superar el nihilismo, como culminación de un pathos que influye en el sujeto. Es una superación desde el nihilismo y desde el ego. Una práctica que, aplicada a la cultura europea, revela el fundamento vacío de sus valores culturales, dado que apuntan a una vida inexistente y niegan la vida presente. Ese es el fruto de vivir los valores nihilistas de la cultura hasta su final en el propio individuo, y es también el punto de partida desde el cual la voluntad de poder puede generar lo que Nishitani define con las palabras de Nietzsche: «el contra-movimiento». Una doctrina basada en nuevos valores que si enfaticen la vida presente. (Nishitani, 1990, p. 32).

\subsection{El cristianismo como causa principal del nihilismo europeo.}

Una vez que hemos visto cómo Nishitani define la investigación nietzscheana del nihilismo y su superación, es el momento de centrar el interés en cómo entiende el contenido de dicha filosofía con relación al nihilismo.

Compartiendo en parte la opinión expuesta en este trabajo, Nishitani considera que se puede rastrear el nihilismo en las obras fundamentales de Nietzsche, pero las tesis de su última elaboración se encuentran en los últimos fragmentos personales y póstumos del autor. El filósofo de la escuela de Kioto lee tales líneas desde su compilación en la obra La Voluntad de poder, lo cual resta legitimidad a su interpretación por la invalidez de esta obra, tal como ha señalado la comunidad 
científica. Una de las últimas refutaciones sobre ella ha sido recordada por Paolo D'Orio, quien comenta que La Voluntad de poder nunca llegó a escribirla Nietzsche, sino que fue una reordenación en contra del verdadero orden cronológico de sus fragmentos personales. Además, en muchos casos el contenido de los textos tuvo que ser deducido, dado que el material se encontraba en muy mal estado. (D'Orio, 2014, p. 159-160).

La mayoría de los fragmentos que Nishitani cita de la obra La voluntad de poder corresponden a los años 1886-1888, donde ciertamente se encuentran algunos apuntes que tratan directamente el problema del nihilismo europeo. Este hecho respalda la interpretación de Nishitani centrada en los Fragmentos Póstumos de Nietzsche. Pero debemos evidenciar los problemas de validez que presenta precisamente la fuente desde la cual toma los fragmentos. De su lectura Nishitani entiende que el diagnóstico del nihilismo europeo está dividido en tres contenidos fundamentales: una definición sobre el nihilismo en sí, otra definición como resultado de la desvalorización de los valores europeos, y por último una crítica de la moral cristiana, de donde se extrae el contenido de ambos nihilismos.

En su lectura sobre el problema del nihilismo a través de Nietzsche, Nishitani deduce que el cristianismo es el principal causante del nihilismo (Nishitani, 1990, p. 33). Esa es la conclusión que se encuentra en los tres capítulos sobre Nietzsche de la obra The Self-Overcoming of Nihilism, cuya composición se divide en dos ensayos. Sobre el origen de ambos textos, Ueda Shizuteru dice que la primera edición de esta obra en su idioma original, fechada en 1949, contenía solo un texto dividido en dos capítulos. En 1952, Nishitani escribió el segundo ensayo titulado Nihilism y Existence in Nietzsche, y en 1966 el autor aceptó incluirlo en las siguientes ediciones de la obra, de las cuales surgió la traducción inglesa que aquí trabajamos. Podemos extraer tres ideas sobre esto: ambos textos no son contradictorios sino complementarios ya que se encuentran recopilados en la misma obra; el primer ensayo se centra en los Fragmentos Póstumos y el segundo en sus obras publicadas; 
y por último en ambos textos se inicia el problema del nihilismo desde el cristianismo. En concreto, en el primer ensayo expone que la doctrina cristiana es la causante del nihilismo, y en el segundo establece el surgimiento del nihilismo con la muerte del Dios cristiano a través de la obra La gaya ciencia.

Con el paso de los años Keiji Nishitani mantuvo su postura de culpabilizar al cristianismo como responsable del problema nihilista europeo. James W. Heisig, expone también los orígenes que Nishitani establece sobre el nihilismo en Europa y Japón.

«En cambio, Japón no se acercó al nihilismo por una sacudida de las fundaciones de la religión, como Europa hizo para con el cristianismo. En lugar de eso, heredó la tecnología y las estructuras sociales del mundo moderno que habían surgido en medio del mismo proceso de agitación espiritual.» (Heisig, 2002, p. 272)

En el primero de los dos ensayos es donde encontramos el fundamento de esta denuncia al cristianismo como causante del nihilismo. A través del fragmento titulado Crítica de la moral cristiana que ya se ha comentado en este trabajo, Nishitani destaca que el pensamiento cristiano es un antídoto contra dos nihilismos esenciales al ser humano: el teórico y el práctico, que Nishitani concibe en conjunto como la definición general de nihilismo, concebido como un pathos existencial del hombre. La moral cristiana dota al ser humano de sentido propio al tener valor absoluto, y también genera una realidad perfecta para él donde tiene libre albedrío. Estas dos ideas son una interpretación del sentido de la existencia y de la vida, y su ausencia sería la aparición de un nihilismo esencial práctico. Por otro lado, la tercera dote de la moral cristiana aporta al hombre un conocimiento trascendente, que permite al ser humano conocer a Dios y entender el sentido de la existencia. Sin esta capacidad el ser humano entendería la razón de la existencia y de la vida no son importantes, dado que son incomprensibles. Ello sería el nihilismo esencial teórico. «But Christian morality, in opposition to this kind of practical or theoretical nihilism, granted absolute value to the human, gave meaning to the world, and left room for wisdom and knowledge about these things. » 
(Nishitani, 1990, p. 34).

Al comienzo de esta obra que estamos citando Nishitani señala que hemos de prestar atención a dos tipos de nihilismo. Un nihilismo transhistórico que acompaña al ser humano fruto de la duda sobre el valor de su existencia y del mundo; y un nihilismo histórico sucedido a través de unos hechos concretos, a una sociedad concreta, y a una cultura contextualizada temporal y geográficamente. (Nishitani, 1990, p. 4). El primer nihilismo transhistórico es aquel que fundamenta una duda propia del ser humano, como ser pensante en la existencia. Es una duda existencial que se ha intentado responder a través de cristianismo y del budismo. El segundo nihilismo en cambio acontece tras la caída del pensamiento cristiano contextualizado, ubicado y denominado cómo nihilismo europeo.

El cristianismo queda establecido como un tipo de cura contra ese doble nihilismo natural del ser humano, dada su necesidad de interpretación sobre un sentido del mundo y de la vida. Sin embargo el contenido de esta religión va más allá, y por ello genera una contradicción que desemboca en el nihilismo europeo. En el apartado Nietzsche's Interpretation of Christianity, Nishitani expone la ya conocida crítica nietzscheana sobre el dualismo ontológico de esta religión. Inicia con una insatisfacción completa por la realidad, y termina generando una realidad alternativa satisfactoria. El sufrimiento, el dolor y el engaño se muestran como factores del mundo en relación al ser humano, y se proyectan la felicidad y el placer en un mundo de eternidad e inmutabilidad. Este tipo de doctrina genera una serie de valores culturales que terminan despreciando lo natural, lo cambiante e incluso la vida. Así surge un valor de lo sagrado en el cristianismo como oposición al valor de lo natural. La grandeza del valor medida por su desnaturalización. Dado que la vida humana es algo evidentemente natural, estos valores son tanto antinaturales como anti-vitales. 
«For him, the imaginary world of Christianity is an expression of deep dissatisfaction with the real world. He speaks in a number of places of the "denaturalization" (Entnatii rlichung) perpetrated by Christianity, by which he means its tendency to see all values rooted in the instincts of natural life as non-values, to consider the negation of natural values-that is, denaturalization-to be rather a "sacralization." In other words, "God" is imagined as something opposing nature, so that for the first time "natural" becomes synonymous with "reprehensible."» (Nishitani, 1990, p. 37-38).

Nishitani evidencia que, aunque esta es la lógica final del pensamiento cristiano, su doctrina fue diseñada con motivo de superar el nihilismo transhistórico, luego dicha valoración nunca tuvo por finalidad el desprecio del mundo terrenal del devenir, sino la salvación humana ante el "abismo de nihilidad". Esta es para él la relación ambivalente del cristianismo con el nihilismo. En su pensamiento, todas las religiones son doctrinas que intentan evitar ese abismo, o mejor dicho intentan responder a aquellas preguntas sobre qué es el ser humano, qué es la existencia, qué es la vida y qué es la muerte, justo como declara en el primer capítulo de su obra La religión y la nada titulado ¿Qué es la religión? (Nishitani, 1992, p. 37-39). Luego en consecuencia, todas las religiones intentan responder al nihilismo transhistórico, en sus aspectos teórico y práctico.

Sin embargo, debido a la dualidad ontológica propuesta por el cristianismo intentando resolver tales interrogantes existenciales y a la compasión, dicha doctrina genera una jerarquía de valores en la que la mayor estima es otorgada al mayor penitente, y en la que el mundo importante se encuentra tras la muerte. Es la compasión de las bienaventuranzas, el elenco de ideales ascéticos que valoran al débil por encima del fuerte y la post-vida por encima de la vida. Por eso propone apreciar la debilidad y despreciar la fortaleza, una idea unida a la igualdad humana ante Dios y que conlleva reducir a todos los individuos «to the lowest common denominator.» (Nishitani, 1990, p. 40).

En resumen, el cristianismo es un antídoto contra el "abismo de la nihilidad", también y una revaloración del sufrimiento que preserva la vida humana de los funestos avatares que le acontece. El valor absoluto del hombre, la creación del mundo perfecto, el ser humano como individuo libre, el conocimiento humano trascendente, la dualidad ontológica de lo terrenal y lo paradisíaco, y por 
último el bienaventurado factor de la compasión, son ideas que surgen con dicha finalidad. Sin embargo, ha acabado generando unos valores de desprecio hacia la realidad terrenal, hacia la vida afincada en ella, y hacia el factor de la fortaleza como verdadera resistencia ante el sufrimiento del mundo del devenir. Cuando según estos valores, surge la refutación del pensamiento cristiano, emerge un nuevo nihilismo que desprecia la única realidad existente y al propio sujeto: se trata del nihilismo radical llamado extremo o europeo. (Nishitani, 1990, p. 34).

\subsection{La muerte de Dios. El auge del nihilismo europeo o de la filosofía libre}

En el ensayo Nihilismo y existencia, donde encontramos esa segunda interpretación antes mencionada del nihilismo de Nietzsche, Nishitani referencia la muerte de Dios como la quiebra de la fe cristiana en Europa. También podríamos decir a estas alturas que el ensayo comienza justo con la refutación del pensamiento cristiano, es decir en la emergencia del nihilismo extremo europeo. Evidencia dos posibles consecuencias de esta sentencia nietzscheana: puede provocar el nacimiento del nihilismo más extremo posible, y también puede ser el momento culminante de la humanidad: la superación de todos los nihilismos. Así entiende que con la desaparición de la omniabarcante interpretación cristiana, se abre un vasto océano de nuevas interpretaciones con las que navegar para re-entender la realidad. «His nihilism emerged with the death of the Christian God, and his existential attitude is that of a seafarer departing on a voyage of dangerous exploration into the vast ocean of life that had opened up as never before through the death of God. » (Nishitani, 1990, p. 70). La muerte de Dios puede generar entonces dos tipos de consecuencias: o es el auge de una nueva filosofía libre, o es la llegada del nihilismo extremo europeo. El progreso de la humanidad o el mayor de sus problemas.

Nishitani entiende así el doble posible sentido de la «muerte de Dios», pero expone que el conjunto del sistema metafísico-ético de occidente ha permanecido como paradigma de 
pensamiento, pese a haber sido de esta manera invalidado. «At any rate, Platonic/Christian metaphysics and its entire system of ethics have become problematic. » (Nishitani, 1990, p. 70) Es decir, puesto que no se ha abandonado el marco de referencia tras su impugnación, este se ha vuelto problemático. No ha permitido la aparición de nuevas interpretaciones. Pese a ser evidente su desvaloración, su fuerza en la cultura occidental es tal que no permite su transvaloración. Y por este hecho, la consecuencia de la muerte de Dios no ha sido la apertura al horizonte filosófico ajeno a la moral cristiana, sino el hundimiento en el más extremo nihilismo posible, el nihilismo europeo. Mantiene esta cuestión sintonía con dos famosas ideas de Nietzsche: la pervivencia de las sombras de Dios en la caverna tras su muerte, y la moral cristiana entendida como la inevitable «Circe del filósofo».

Estos son los motivos por los que Nishitani denuncia a la religión cristiana como la causante del nihilismo europeo, y establece la equivalencia de este con los denominados "radical" o "extremo". Cabe decir que no obvia la cuestión de los valores metafísicos, dado que también habla del fragmento La crítica de los valores cosmológicos, (Nishitani, 1990, p. 34) pero acepta que la extensión de tales valores se produce en la sociedad europea a través de la expansión del cristianismo, y así centra su atención en este último. Tener en cuenta a la metafísica como otros de los orígenes del nihilismo, algo propio de las interpretaciones de Nietzsche, implica la separación de los conceptos metafísica y religión, una división establecida desde la filosofía de Occidente. Sin embargo, tanto para Keiji Nishitani como para otros autores de la escuela de Kioto, la filosofía es una totalidad compuesta de ciencia, metafísica y religión; y de hecho consideran la cultura de un pueblo como el conjunto de ideas y valores científicos, filosóficos, metafísicos y religiosos. (Heisig, 2002, p. 37-38). Esta concepción nos ayuda a entender la reducción de Nishitani sobre las causas del nihilismo al enfocarlas todas en el cristianismo. 


\section{La auto-superación atea del nihilismo europeo. Nietzsche a través de Nishitani}

Ha quedado reseñado que Nishitani entiende el factor del cristianismo como la principal causa del nihilismo europeo de Nietzsche. La caída absoluta de la religión cristiana es el fenómeno que hace brotar un nihilismo más extremo y radical, la versión europea de este problema. En este sentido se podría pensar que la religión en el mundo moderno estaría condenada a la extinción. Sería el desencantamiento del mundo el único modo de afrontar y superar el pathos nihilista.

Nishitani referencia en sus obras trabajadas aquí dos formas de auto-superar el nihilismo europeo. El problema se hace presente gracias a Nietzsche y a través del propio autor se alcanza una auto-superación, luego una praxis hermenéutica de su filosofía nos puede llevar a descubrir el nihilismo y auto-superarlo. En principio parecería que no deberíamos ahondar más en esta cuestión, podríamos seguir la interpretación que Nishitani realiza de Nietzsche para terminar con el problema. Sin embargo, el filósofo budista defiende que su actualidad no se circunscribe al nihilismo europeo de Nietzsche, sino a sus consecuencias dado que no se ha desarrollado la su auto-superación. Si la metodología de la Existenz consiste en vivir el pasado de la historia y utilizar sus recursos culturales para alzar el contra-movimiento, entonces Nishitani considera que un nuevo diagnóstico centrado en las consecuencias del nihilismo es la clave para desarrolla una nueva auto-superación. Para Nishitani esa nueva auto-superación avanza por un nuevo camino religioso.

En conclusión, hemos de comentar dos vías de auto-superación del nihilismo: la interpretación que Nishitani extrae de la consumación nietzscheana del nihilismo, y la propia superación que Nishitani desarrolla al amparo de su pensamiento budista Zen. Son respectivamente una auto-superación atea y religiosa del problema nihilista europeo.

\subsection{Del diagnóstico a la auto-superación. Las tres transformaciones del espíritu}

El problema del nihilismo exige para Nishitani una vía de auto-superación, lo que significa 
que el sujeto debe superarlo a través del nihilismo y a través de sí mismo. En este contexto las tres transformaciones del espíritu que descubre en Así habló Zaratustra de Nietzsche, muestran como el nihilismo ha de superarse en tres etapas (Nietzsche, $A H Z, 2003$, p. 52-54). Las dos primeras implicarían el paso de un nihilismo inconsciente a un nihilismo consciente, y la tercera etapa sería la generación de nuevos valores. Luego padecer el pathos de lo «en vano» y descubrir el diagnóstico del problema son ya las dos primeras fases de la auto-superación.

En su ensayo el filósofo budista relaciona las etapas del espíritu en Nietzsche con uno de sus Fragmentos Póstumos denominado El camino hacia la sabiduría, donde encontramos tres pasos con elementos cercanos a los tres espíritus nietzscheanos. (Nietzsche, FP. Vol III 2010 [1884], 26 [47], p. 548.).

La primera etapa consiste en la transformación del espíritu humano en camello. La figura hace referencia a un animal que se arrodilla, un animal que carga los valores que dificultan la vida. Nishitani deduce que para superar el nihilismo europeo se requiere una formación completa en el pensamiento religioso y metafísico. El individuo debe profundizar en aquellos valores que apuntan hacia otro mundo, es decir, que afirman la vida y la existencia a través de una segunda existencia ideal, fija, eterna y verdadera. Es un ejercicio de voluntad de poder y una auto-afirmación de la vida, pero subyugada a una segunda existencia. En su pensamiento el camello es el resultado del uso del cristianismo como antídoto contra ese nihilismo natural teórico y práctico. Una superación del problema que no defiende este mundo, sino uno posterior.

«From this point on, Existence as nihilism begins. The bearing of burdens, reverence; and cultivation through the religious or philosophical life represent a preparatory stage. The transformation into the camel, the first stage on the path to wisdom, involves both immersing oneself in the teachings of traditional religion and metaphysics as well as a turn to nihilism which breaks through them. It involves what was spoken of earlier as a turn to the unconscious nihilism at the core of religion and metaphysics, and from there to true, conscious nihilism. The stimulus for this turn, that which drives the camel into the desert, is provided by the virtues of honesty and truthfulness cultivated by the morality of religion. » (Nishitani, 1990, p. 82) 
En conclusión, la inmersión en el nihilismo es el primer estadio de su superación, esto indica que no se pueden transvalorar los valores sin antes cargar con ellos. El peso de los valores y la soledad del camello iniciará el segundo paso, su transformación en león.

Esta segunda transformación está caracterizada por la introspección que el individuo realiza en torno a los valores aprendidos. Tal es el sentido para Nishitani de la soledad del desierto y del peso de los valores. El animal profundiza sobre el porqué de sus valores y cuando evidencia la nulidad de su fundamento se transforma en un león para despedazarlos. La transformación en camello, luego en león y su capacidad para destruir los valores coinciden Nishitani con su interpretación de la Existenz nietzscheana. También denomina esta etapa como the diphasic wave of atheism: esta expresión señal que el fruto de la Existenz es una doble refutación externa e interna, científica y psicológica, de la idea de Dios. De esta manera el nihilismo que se había vuelto inconsciente gracias a la doctrina cristiana ahora vuelve a emerger en la consciencia, pero en forma de un nihilismo radical, extremo, europeo.

«In the first phase the existence of God was put into question and was denied by the world view of the natural sciences; and in the second, the concept of God was explained psychologically and historically, and an ironical way of thinking emerged which cut it off at the roots. The spiritual basis of Christianity was for the first time undermined, and the mood of "the death of God" emerged. This marks the advent of "true nihilism," the self-conscious nihilism that Nietzsche calls "European nihilism."» (Nishitani, 1990, p. 76-77)

Podríamos decir que el león es la conciencia científica, psicológica y filosófica que desoculta por completo el nihilismo, lo hace consciente. Nishitani evidencia sobre esto la tesis de Nietzsche de que el pensamiento científico de su época aún no ha completado esta fase dado que aún defiende el valor de la verdad en el conocimiento. Por eso entiende que para completar la fase del león el conocimiento debe abandonar la verdad, considerada una de esas «sombras de Dios». Rechazar el sentido absoluto de la verdad y finalizar la etapa del león permite iniciar su 
transformación en niño, el tercer paso y el comienzo de la transvaloración de los valores como autosuperación del nihilismo.

El tercer paso o tercera transformación del espíritu en niño es definida por Nishitani a través de la expresión «Existence as body». Considera que es el momento en el que se afirman los nuevos valores, aquellos que Nietzsche establece como superación del nihilismo: amor fati, auténtica voluntad de poder, sinceridad, ego fatum y eterno retorno. Expone una reflexión a través del Zaratustra, entendiendo que con los nuevos valores surge una división del nihilismo, una doble interpretación de esta idea. Dos interpretaciones corporales que conciben el nihilismo desde su estado de salud: un estado enfermo fruto de los valores tradicionales, y un estado sano fruto de la liberación de esos valores. Por ello el cuerpo enfermo es aquél que inventa el mundo del más allá y el mundo no habitado por él sino por el alma, mientras que el cuerpo sano es el niño con el punto de vista de la creación, la voluntad, y la valoración positiva de sí mismo.

«Nietzsche says that it was not "soul" or "spirit" that made people invent a world beyond, or a God behind this world and beyond the world inhabited by the body, but rather the sick and exhausted "body" itself. [...] Nietzsche also speaks of "the voice of the healthy body [as] a more honest and purer voice." Therefore the healthy "body" is the standpoint of the creating, willing, and valuing "I" itself, [...]» (Nishitani, 1990, p. 94-95)

Para Nishitani esta tesis nietzscheana tiene relación con ese aspecto de la verdad y la ciencia que comentábamos. Es la ciencia entendida en relación con el cuerpo la que se desliga por completo de la verdad por la utilidad. La ciencia enfocada en la existencia humana y no en la verdad aplica sus métodos para conocer la mejor forma de vivir, fortalece al ser humano. De la voluntad de verdad pasa a una voluntad de fortaleza. Se justifica en esta explicación uno de los factores fundamentales de la superación del nihilismo, rechazar la idea de verdad absoluta. Es un punto de vista científico ajeno a la moralidad, donde los conceptos verdad y mentira se entienden desde un 
punto de vista extramoral, como útiles para la civilización humana (Nietzsche, SVM, 1996). Dado que el cuerpo enfermo genera el sentido nihilista de la vida, la ciencia unida a la idea de Existenz nietzscheana desarrolla una mejora del cuerpo, es decir, el cuerpo sano de donde se construye el sentido afirmativo del nihilismo y la auto-superación a través de los nuevos valores metafísicos.

\subsection{Nuevos valores. Voluntad de ilusión, sinceridad, amor fati y ego fatum}

La auto-superación nietzscheana del nihilismo europeo implica una concepción concreta de la epistemología entendida como conocimiento ilusorio. El conocimiento del mundo es una labor descubridora de ilusiones, pero no de verdades. Nishitani entiende de esta manera que en la filosofía nietzscheana el verdadero significado del mundo no existe, pero la voluntad de poder impulsa la necesidad humana de dar significado. Entonces esa voluntad de poder es voluntad de ilusión. «There is no such thing as a "true" world that has nothing to do with us; conversely, what we interpret as the world is always an illusion, and this illusory world a "perspective" of will to power.» (Nishitani, 1990, p. 45). En consecuencia, la importancia de la metafísica no radica en su contenido, sino en los valores que la sustentan. Tienen la misma validez desde la interpretación más poética hasta la interpretación más rigurosa, es en síntesis una defensa del perspectivismo. La axiología metafísica debe enfocarse en afirmar tanto la vida como la existencia, dado que esa valoración fortalece la relación del ser humano con la realidad. En base a esta interpretación del filósofo japonés toda metafísica debe de buscar valores afirmativos y evitar valores negativos. (Nishitani, 1990, p. 46-48).

El primer valor que Nishitani deduce para una auto-superación nietzscheana es la sinceridad. El valor de la verdad debe ser sustituida por el valor de la sinceridad, lo que permite al sujeto no dejarse engañar por las interpretaciones metafísicas. Si somos sinceros con nuestra propia forma de ver el mundo, toda voluntad de poder defendida como voluntad de verdad se revelará 
como voluntad de ilusión. Se considera necesario aplicar el valor de la sinceridad y desechar el valor de la verdad, aceptar el matiz ilusorio de toda metafísica.

\begin{abstract}
«To return self-consciously to the will to deception by negating the will to truth, to revolt against the creative will and lie against life, constitutes sincerity toward life. This also means, as I said before, that the story of the progress of interpreting the value of the world, a string of lies all the way to the end, arrives at a new perspective and opens on to a new horizon. What Nietzsche calls the constant fabrication of new lies is therefore a new development of becoming. » (Nishitani, 1990, p. 47.)
\end{abstract}

La sinceridad como valor promueve que toda metafísica sea tratada como ilusión y rechazada como verdad absoluta. Está relacionada con la Existenz dado que es necesaria ese tipo de introspección vital sobre nuestros valores históricos para revelar su carácter ilusorio.

Ahora bien, la metafísica como voluntad de ilusión arraigada en el valor de la sinceridad no impide generar nuevas dualidades ontológicas. De hecho la ilusión podría justificar nuevos mundos divinos. Se necesita por ello un nuevo valor que centre toda la atención en el mundo del devenir. Así se nos presenta el valor amor fati, amar los hechos del mundo del devenir por encima de cualquier otro mundo posible, no cambiar nuestra realidad por ninguna otra fantasía. Por tanto tenemos un perspectivismo, una infinidad de posibilidades de interpretaciones del sentido, cuya ilusión queda siempre demostrada gracias al valor de la sinceridad, y cuya atención queda circunscrita a los acontecimientos del mundo del devenir gracias al valor del amor fati. «The standpoint of amor fati demands that the will, which can differ infinitely, conform itself to the world, which cannot be different. » (Nishitani, 1990, p. 49).

El valor del amor fati presenta no obstante dos problemas para Nishitani: el problema del destino y su posible defensa del fatalismo.

La idea de amar los hechos de este mundo apreciándolos por encima de cualquier otro hipotético, podría acabar defendiendo un progreso de este mundo hacia otro mejor, estableciendo una meta o destino al mundo devenir, la posibilidad de la utopía. Considerar que el devenir de la 
realidad debe dirigirse a un propósito a un destino que se encuentra accesible en el mismo mundo. Este tipo de pensamiento podría generar el desprecio hacia la realidad del devenir presente, lo considera rechazable en pos del destino que debe alcanzar.

\begin{abstract}
«Nietzsche says that when an "other world" is posited behind this world of becoming, it gives the impression that this world could be otherwise than it actually is. This thereby "annuls necessity and fate" in the world, and renders it useless "to submit" to its necessity and "to conform oneself to it."» (Nishitani, 1990, p. 48)
\end{abstract}

Por tanto, Nishitani encuentra en Nietzsche el valor fatum aplicado a este mundo presente del devenir. La voluntad de ilusión puede desarrollar una cadena de infinitas interpretaciones metafísicas que deben albergar, por lo menos hasta ahora, la sinceridad, el amor fati y el destino o fatum.

El segundo problema al que nos enfrentamos es la defensa del fatalismo. Amor fati significa según Nishitani amar los hechos de este mundo tal y como son. Ni siquiera el destino del mundo puede señalar otra realidad diferente de esta, y ello puede ser interpretado como un tipo de fatalismo. Dicha relación no es beneficiosa, pues el fatalismo es idéntico a la consideración de una divina providencia que fija el destino de todas las cosas. Es una posibilidad de contradicción a través de la idea del amor fati, presenta una cercanía a la idea de voluntad divina que podría desarrollar nuevamente el problema nihilista. Nishitani entiende el fatalismo como una sombra del Dios muerto.

Para responder a esto encuentra en los textos nietzscheanos una relación entre el valor amor fati y otro tipo de fatalismo que superar esta contradicción. Se trata del "más alto fatalismo", donde la necesidad es identificada con el azar y la creatividad del devenir del mundo. Consiste en aceptar que los hechos suceden en el mundo con independencia de nuestra concepción, luego es igual entenderlos desde una posibilidad o desde múltiples posibilidades. Si el fatalismo sería la desaparición del azar y creatividad en el devenir dado que sus procesos son necesarios, este otro 
fatalismo considera que los elementos necesarios en el mundo son el azar y la creatividad. Se trata de un fatalismo opuesto, en lugar de imponer un determinismo, determina la necesaria existencia de azar y creatividad. En conclusión el valor del amor fati trae consigo una serie de nuevos valores: el destino, el azar y a la creatividad. Son necesarios para la nueva interpretación en un sentido fatalista, esto es, la realidad no debe ser entendida sin ellos. Para Nishitani esta es la complejidad que se esconde tras el concepto nietzscheano ego fatum, el destino situado en la realidad humana a través de su propia creatividad, de su voluntad de ilusión.

«In opposition to ordinary fatalism, which makes the world-process necessary in such a way as to destroy chance or creativity, Nietzsche advocates a fatalism in which they are as such immediately identical with necessity. The identity of necessity and chance, of fate and the "play" of will, is possible only by virtue of the creating self. [...] Only from the standpoint of the creative self can chance and necessity come together as one. This is also expressed in Nietzsche's idea that "self is fate" (ego fatum). » (Nishitani, 1990, p. 49.-50).

Cabe aclarar que el valor del amor fati no solo significa amar el mundo del devenir tal como es en su presente más inmediato. Nishitani evidencia que en Nietzsche también encontramos un amor por el presente y por todos los hechos pasados que lo conforman. Lo que ha sucedido tanto en la historia como en la vida humana, han sido una sido una serie de hechos que han condicionado nuestra realidad tal y como es actualmente. De manera que el amor por los hechos presentes implica también un amor por todo lo acontecido. Si afirmamos nuestra vida actual también hemos de afirmar todos los aciertos y errores, placeres y dolores, que a lo largo de nuestra vida nos han llevado hasta este punto. (Nishitani, 1990, p. 50-51.) En este sentido de amor fati se hace presente además la necesidad de superar el nihilismo a través del propio nihilismo. Sobrepasarlo es un nuevo avance de la humanidad que no sería posible sin el establecimiento de esta cuestión. La ascensión humana ha necesitado de ese conflicto como manera de superación. El pathos nihilista debe vivirse si desea ser superado.

Voluntad de ilusión, sinceridad, amor fati y ego fatum son los valores afirmativos de la vida 
y la realidad en toda interpretación metafísica. Son el fruto de la transvaloración de los valores que auto-supera el problema del nihilismo.

\subsection{El sentido del mundo nietzscheano. El eterno retorno y el momento.}

La interpretación metafísica que Nishitani deduce de la filosofía de Nietzsche se basa en el concepto de eterno retorno entendido como un sentido del mundo centrado en el presente, el momento que vive el sujeto y que adquiere el atributo de eternidad. Por ello se define con la expresión “el momento y la eternidad”. (Nishitani, 1990, p. 53-57)

En pocas palabras, esta interpretación metafísica concibe que el momento presente del mundo del devenir es toda la realidad conformada a través de todo lo acontecido, fruto del azar y de la creatividad. La razón de aplicar el concepto eternidad surge al considerar que toda la realidad es el momento presente que vivimos en el mundo del devenir, por ello ese presente es la eternidad de la existencia.

\footnotetext{
«The search for eternal life in another world that transcends the world of becoming is, of course, negated by Nietzsche in his radical pursuit of the nihility that such an other world hides from view. For him only the world in which all things are in ever-changing flux remains. [...] This is the absolute affirmation of life, the form of life that affirms itself absolutely. There is the eternity in the midst of the transiency of becoming; [...]» (Nishitani, 1990, p. 54.)
}

En esta interpretación Nishitani considera que el momento presente del mundo del devenir está conformado por todas las cosas que han sucedido y que suceden en ese instante. Esto implica que son necesarios todos los elementos del pasado para conformar el presente, el momento. Sin embargo todos los elementos del futuro llegan precisamente a través de ese presente. Por ello se entiende el momento presente como eternidad al concebir que en ese instante se encuentra todo pasado y todo futuro. «At this present moment the eternal past is all pulled back into the present. The eternal future, too, passes through this moment. At this present moment, both the eternal past 
and the eternal future are pulled back into the present in their entirety, from opposite directions, in such a way that they overlap. » (Nishitani, 1990, p. 58) Es una concepción en la que no hay ni inicio ni final del tiempo, sino dos direcciones temporales y opuestas que se cierran circularmente en el momento presente y. Esto implica considerar la temporalidad de la existencia como un anillo.

En esta concepción circular y cerrada del tiempo y de la existencia, el devenir y el cambio constante del tiempo no pueden dirigirse a ningún lugar ajeno a esta realidad. La dirección del tiempo no puede proponer ningún destino fuera del mundo del devenir. Por ello es una concepción fruto de los valores ego fatum y amor fati. Parece evidente una concepción circular del tiempo cuya dirección del devenir no sea otra que la repetición de todos los hechos. Por tanto, no es solamente que la existencia sea un eterno momento del presente circular, sino que además su devenir es una dinámica condenada a repetirse eternamente. Nishitani señala la idea nietzscheana de que el impulso del devenir es la voluntad de poder, el mismo impulso con el que se interpreta la realidad. Si la realidad es interpretada como una eterna repetición donde el sujeto afirma la vida, la mayor voluntad de poder posible es la sentencia de Zaratustra, donde la vida se afirma hasta el extremo de que, una vez vivida, se desea que se repita (Nishitani, 1990, p. 62). Este sería el resultado de una metafísica nietzscheana que se encuentra más allá del nihilismo y que además no puede volver a decaer en él.

Finalmente, Nishitani señala que esta interpretación del mundo como eterno retorno es una concepción que lucha contra el espíritu de la gravedad o la melancolía, descripto por Nietzsche. Una fuerza cuyas características son equivalentes al problema del nihilismo. Dado que esta interpretación vence a dicho espíritu, considera al eterno retorno como la auto-superación del nihilismo en Nietzsche. Una reinterpretación del mundo obra del Ultrahombre.

\section{La auto-superación religiosa del nihilismo. El punto de vista de la vacuidad}




\subsection{El problema nihilista en el mundo occidental}

Como hemos podido ver, Keiji Nishitani considera acertado el diagnóstico del nihilismo europeo y factible la auto-superación entendida a través de la filosofía de Nietzsche. En este sentido la auto-superación nietzscheana del nihilismo es una vía para solucionar este problema. Sin embargo, para Nishitani su contemporaneidad no se ajusta al problema del nihilismo tal como lo describe Nietzsche, sino a sus consecuencias por no haberlo superado en su momento. Estando en consonancia con los expertos en la materia aquí citados (Volpi, 2004, p. 15-16) y (Sánchez Meca, 2010, p. 12), la cultura occidental es aún nihilista y vive los resultados de este problema. En este sentido el nihilismo descrito por Nietzsche es para él un fenómeno histórico y geográfico, fruto de las respuestas refutadas que habían dominado Europa durante más de dos mil años de historia.

«The worldview that had supported the spiritual life of Europe for more than two thousand years was all at once thrown into question. Faith in God and the eternal world and their accompanying conceptions became no more than historically conditioned ideas. What had once been considered trans historical now began to be seen as products of history. » (Nishitani, 1990, p. 6)

Debido a esto, el pensador budista entiende que las filosofías contemporáneas ateas existencialistas y humanistas del siglo $\mathrm{XX}$ han sido auto-conscientes del nihilismo, gracias a Nietzsche. Tales sistemas de pensamiento señalan según él dos ideas fundamentales: en primer lugar, son evidencias de que este "abismo de nihilidad" no ha sido superado a lo largo del siglo XX, y en segundo lugar demuestran que Occidente tiene una serie de recursos culturales propios para auto-superar el nihilismo. De esta manera Nishitani deduce que la capacidad occidental para superar el nihilismo se encuentra en sus propias bases culturales, espirituales y filosóficas. «The West still has the faith, ethics, ideas, and so forth that have been handed down from Christianity and Greek philosophy, and the integration of these various elements is still the dynamic force behind the formation of the person. » (Nishitani, 1990, p. 175)

Sin embargo, Nishitani destaca el caso excepcional de Japón como ejemplo de país 
occidentalizado. También se ha comentado ya esto en las líneas referidas a la relación vital que Nishitani tiene con el nihilismo. Japón es, como el propio filósofo de Kioto destaca, fruto de la europeización de finales del siglo XIX y de la americanización de mediados del siglo XX. En principio nos advierte que las bases del pensamiento y de la cultura occidental no fueron importadas a Japón, y por tanto el problema nihilista occidental no es el suyo. «The spiritual basis of Europe has not become our spiritual basis. » (Nishitani, 1990, p. 174). Fueron las bases culturales de Japón, que según Suzuki eran precisamente los valores del budismo Zen (Suzuki, 2006, p. 103) las que se preocuparon de que Japón despertara a la modernidad europea renovando su estado, su economía y demás instituciones. En ese despertar el pueblo japonés sufrió una desvalorización y abandono de las propias bases culturales japonesas. Dicho con otras palabras, según Nishitani el pensamiento budista Zen motivó a Japón a realizar esa aculturación occidental, sin sospechar que conllevaría una desvalorización de sus propios valores supremos. Este sería un diagnóstico diverso del realizado por Nietzsche, pero tiene como podemos ver un resultado idéntico.

\begin{abstract}
«Up until the middle of the Meiji period a spiritual basis and highly developed tradition was alive in the hearts and minds of the people. Indeed, the reason Japan was able to take in western culture with such unprecedented alacrity was that people then were possessed of true ability born of spiritual substance. However, as Europeanization (and Americanization) proceeded, this spiritual core began to decay in subsequent generations, until it is now a vast, gaping void in our ground. [...] The worst thing is that this emptiness is in no way an emptiness that has been won through struggle, nor a nihility that has been "lived through." It is the natural result of our having been cut off from our tradition. Before we knew what was happening, the spiritual core had wasted away completely. » (Nishitani, 1990, p. 175)
\end{abstract}

Nishitani concluye por ello que la filosofía nietzscheana no solo presenta el problema del nihilismo, sino que a través de ella podemos diagnosticar el problema en países occidentalizados que también hayan sufrido una desvalorización de sus propios valores. Dos tipos de nihilismos podemos deducir: aquel propio de la cultura europea u occidental, y aquel encontrado en un país occidentalizado que ha desvalorizado sus propios valores. Son a su modo de ver dos caras de la misma moneda (Nishitani, 1990, p. 178). Por tanto, el nihilismo actual es un problema bifacético 
cuya extensión abarca actualmente el mundo occidental, considerado como aquel espacio geográfico compuesto por Europa y países occidentalizados. Gracias a esta reflexión Nishitani evidencia la respuesta: si para afrontar el nihilismo Europa tiene sus propias bases, entonces los países occidentalizados tienen que recuperar las suyas, lo cual no es directamente un deseo de regresar al pasado, sino en todo caso afrontar los problemas del presente recuperando los valores autóctonos que se han perdido. Redescubrir el pasado de un pueblo en su presente nihilista con el fin de auto-superarlo. En parte una idea que se aproxima a su interpretación nietzscheana sobre la Existenz.

Por ello en conclusión defiende la necesidad de analizar las consecuencias del nihilismo tanto en países occidentales como en países occidentalizados con el fin de generar nuevamente la auto-superación. El nuevo diagnóstico y la nueva terapia deben encajar con la filosofía nietzscheana, es decir, no defender aquellas ideas que el propio Nietzsche critica en su pensamiento.

\subsection{Ciencia, filosofía, religión y vida cotidiana.}

James W. Heisig reseña un argumento que engloba dos obras de Nishitani: Una filosofía de la subjetividad elemental, y La Religión, la historia y la cultura. Comienza con una definición de religión como un despertar a un tipo de subjetividad o percepción del mundo desde el sujeto, más primordial y elemental que nuestra percepción cotidiana y científica. Esa subjetividad observa la realidad como una naturalidad elemental, el conjunto de todas las cosas vistas desde su mismidad o esencia, incluida la del propio observador. Es una definición de religión acuñada a través del budismo. El ensayista Juan Arnau nos comenta en su trabajo sobre esta religión que en ella se encuentra el concepto bodhi, despertar, como una manera de percibir verdaderamente la realidad donde la mente se considera un sentido adicional (Arnau, 2007, p. 77-78). En esta definición de religión se señala el objetivo del conocimiento verdadero de la realidad, y Nishitani destaca que ese 
es también el interés del trabajo científico y filosófico. No obstante, estos dos últimos puntos de vista descalifican cualquier perspectiva basada en una fe. Las tres ópticas son desde el punto de vista de Nishitani resultado de la cultura, de la historia y además se interrelacionan entre sí. De modo que, si las perspectivas de la razón declaran la independencia con respecto a la perspectiva de la fe, entonces están entrando en una evidente contradicción.

Haciendo referencia en este sentido al racionalismo occidental moderno, Nishitani considera que ese deseo de independencia es reactivo. Surge ante el orden de cosas previo en el cual la fe tenía cierta independencia de la razón. Para él ambos casos son contradictorios ya que entiende cultura, historia, fe y razón como una totalidad. Entonces Nishitani concluye que la razón no alcanza la naturalidad elemental por negarse a colaborar con aquellos aspectos culturales que influyen en ella, en este caso el de la religión. Por el contrario, su idea de religión engloba cultura, historia y razón, y por ello justifica que es el modo correcto de ver el fundamento elemental de la realidad. (Heisig, 2002, p. 245 - 247) Este modo de razonamiento formara parte de su diagnóstico sobre el nihilismo actual y de su nueva metafísica de auto-superación.

Una segunda elaboración de esta reflexión es el inicio de la opera magna de Nishitani La Religión y la nada. Allí expone que la epistemología, entendida como la labor científica y filosófica, tiene un problema: una desconexión completa entre sus disciplinas científicas, científicosociales, sus discursos metafísicos y su visión cotidiana del mundo. Además de impedir una visión de un conjunto, disciplinas y discursos mantienen pugnas donde refutan los argumentos contrarios e intentan validar los suyos. Defiende que esto es una incapacidad de encontrar el sentido de la existencia que permita responder a las preguntas esenciales del ser humano. El origen de este conflicto lo sitúa Nishitani en el campo de conciencia: una contemplación de la realidad desde el punto de vista del sujeto, donde todo lo ajeno a él es objeto. 
«Considerar las cosas desde el punto de vista del yo es verlas siempre como meros objetos, es decir, examinar las cosas desde fuera de la esfera interna del yo. Esto quiere decir asumir una posición frente a las cosas desde la cual el yo y las cosas permanecen separados uno de otro. Este punto de vista de separación sujeto-objeto, u oposición entre interior y exterior, es lo que llamamos el campo de la conciencia.» (Nishitani, 1999, p. 46)

El origen de este campo queda situado en la distinción cartesiana de res cogitans y res extensa, donde la conciencia subjetiva piensa la realidad como algo externo a él, algo ajeno, el objeto. Impone una barrera infranqueable entre el sujeto y el conjunto de los objetos que forman el predicado de la realidad. En esta división y frontera se basa el sentido de la realidad, de carácter mecanicista y teleológico, que considera el funcionamiento del mundo mediante de leyes fijas y con una intención humana: el objetivo de dominar el entorno mediante un conocimiento instrumental cuyo resultado es la tecnología. En resumen, del campo de conciencia fraguado en la dicotomía sujeto-objeto, surge una visión científica de la realidad, cuyo objetivo es el dominio tecnológico de las leyes que rigen los cambios del mundo.

Esta reflexión continúa en el capítulo Nihilidad y Śūnyatā, donde se aborda el marco de la pugna entre ciencia y religión. Para Nishitani, existen cuatro perspectivas desde la cual conocer la realidad: religiosa, filosófica, científica y cotidiana. El conocimiento científico en general procede del campo de conciencia, pero las doctrinas religiosas y las filosofías se fraguan por igual en sistemas metafísicos y ontológicos, estén fundados desde el campo de conciencia o no.

«La visión del mundo que predomina en la ciencia y, en general, la forma científica de pensar parecen ser fundamentalmente incompatibles con la visión del mundo y la ontología que han constituido las bases de las religiones tradicionales. Ahora bien, la objeción que puede surgir respecto a estas visiones del mundo y ontologías es que, mientras puedan ser atribuidas a la metafísica o a la filosofía, no son consideradas religiosas ni mantienen relación con la vida esencial de la religión. En ello, hay parte de verdad, pero no es del todo cierto. Cada religión, cuando adopta su forma concreta -como una realidad histórica efectiva-, siempre se basa en alguna visión del mundo u ontología.» (Nishitani, 1992, p. 129)

Nishitani expone que no solo existe una pugna establecida entre la ciencia y los sistemas metafísicos y ontológicos de la filosofía y la religión, sino que además la visión científica es la que 
tiene mayor vigencia, gracias a su conocimiento objetivo y demostrable empíricamente. La ciencia desbanca por ello las otras perspectivas. Sin embargo propone que esa victoria científica es pírrica, dado que siempre concluye en hipótesis y teorías. El problema surge debido a la actual autoridad y poder de la ciencia, que permite defender esas hipótesis y teorías como hechos contrastados e irrefutables ante cualquier otro conocimiento.

«Por eso, las explicaciones científicas, aunque sean intrínsecamente hipotéticas, siempre son presentadas como hechos objetivos. Esto puede explicarse por el poder único que disfruta la ciencia, por la autoridad con que ha sido investido el científico.» (Nishitani, 1992, p. 130)

En sí el conocimiento científico, dada su parcelación inconexa, ya presenta un problema a la hora de conocer la realidad, dado que lo hace de forma fragmentada y en conflicto. Debido a ello y a su método de hipótesis y teorías que nunca van más allá de lo empírico, es un saber incapaz de responder a las preguntas fundamentales que la filosofía y la religión si abordan. Cabe decir que esta tesis es muy próxima a la idea que Franco Volpi reseña sobre la última conferencia en Munich de Max Weber. Allí el sociólogo expuso a principios del siglo XX que la racionalización científica se disponía a realizar un desencantamiento del mundo, eliminando la vigencia de las concepciones religiosas, lo cual desde su punto de vista era positivo. Pero al mismo tiempo reseñaba que la ciencia y su metodología era incapaces de aportar valores y sentidos últimos de la realidad, lo que conllevaba una futura existencia de Occidente ajena a estas ideas. (Volpi, [1996], 2004, p. 74-75) En conclusión, Nishitani señala en este sentido que la ciencia es notable en destrucción de conocimiento pre-científicos, pero los campos humanos, existenciales y metafísicos exceden su capacidad.

\subsection{El deseo de libertad y la orientación científica}

Amén de estos problemas, en la omniabarcante autoridad y práctica del conocimiento 
científico expone Nishitani el problema del actual nihilismo. Desde su punto de vista el conocimiento científico del mundo se estructura en tres niveles de leyes científicas: físico-químicas que afectan por igual a seres inorgánicos y orgánicos, biológicas que afectan a seres orgánicos, y psicológicas que afectan a seres orgánicos, pero de forma especial a seres orgánicos inteligentes.

De esta estructura deduce que el conocimiento de las leyes se justifica cuando los hechos del mundo del devenir se manifiestan conforme a ellas, es decir, cuando en su actividad demuestran regirse por tales leyes, así su contenido adquiere plena actualidad. «Las leyes naturales sólo se ponen en evidencia cuando esos organismos viven y actúan, y, por tanto, encarnan esas leyes y se las apropian. La hegemonía de las leyes de la naturaleza sólo se evidencia en el mundo de las cosas concretas cuando las leyes son actualizadas por esas cosas.» (Nishitani, 1992, p. 132)

Pero tal como se ha aclarado previamente, el conocimiento científico es de carácter teleológico, las leyes se investigan y se descubren con motivo de generar una aplicación tecnológica que permita su dominio. La finalidad del conocimiento científico es la formulación y el control de las leyes científicas a través de la tecnología, las cuales rigen los movimientos de las cosas y de los seres vivos, incluidos los del ser humano. Por tanto, la finalidad del conocimiento científico es la inversión del dominio, que el hombre controle las leyes de la naturaleza. Tal objetivo es fruto de un deseo de libertad suprema. (Nishitani, 1992, p. 136). Liberarse subordinando la ley a través de la máquina.

En consecuencia, el ser humano expande su control a través de la expansión de la máquina. Para Nishitani la máquina es fruto de la materia prima transformada hasta el punto de dejar de ser naturaleza, y luego manipulada por el ser humano en un trabajo mecánico en cadena que elimina toda creatividad y humanidad de su labor. En suma, la máquina es fruto de una naturaleza desnaturalizada y de una humanidad deshumanizada. Para esta suprema liberación el ser humano necesita extender las máquinas al ámbito de su vida cotidiana. Este es un proceso de mecanización 
de la vida humana cuya profundidad va aumentando hasta que la máquina acaba rigiendo las vidas de los sujetos, y entonces se produce una inversión de control. El ritmo de la máquina acaba dominando la vida humana.

\begin{abstract}
«Cuando esta relación de control recíproco entre las leyes naturales y las cosas de la naturaleza alcanza su extremo en la máquina, se produce en un lugar que va más allá de los lazos originarios y naturales entre el hombre y el mundo de la naturaleza. Esta relación rompe la barrera entre la humanidad del hombre y la condición natural de la naturaleza, y al hacerlo se radicaliza completamente. Pero, al mismo tiempo, en ese extremo se produce una tergiversación: una inversión de la relación más elemental en la que el hombre tomaba el control de las leyes de la naturaleza, [...] por medio del control que esas leyes efectuaban sobre la vida y el trabajo del hombre; ahora, las leyes de la naturaleza vienen a retomar el control sobre el hombre que las controla. Se suele llamar a esta situación la tendencia hacia la mecanización del hombre, hacia la pérdida de lo humano.» (Nishitani, 1992, p. 137-138)
\end{abstract}

En conclusión, la máquina permite dominar la ley por el hecho de que el ser humano controla la máquina, pero en el momento en el que la vida se mecaniza es la máquina quien comienza a regir el devenir del hombre, y como dominadora de la máquina vuelve a quedar la ley. El ser humano, en su deseo de liberación ante las leyes de la naturaleza, desarrolla un desarraigo con la realidad para evitar su dominio. Dicho con las palabras de Nishitani: «Aquí, la normatividad de las leyes de la naturaleza, llevada al extremo de un profundo control interno del hombre, evidencia un modo de ser en que el hombre se comporta como si permaneciera fuera de las leyes naturales. [...], éste es un modo de ser en cuyo fondo se ha revelado la nihilidad.» (Nishitani, 1992, p. 138)

Este es por tanto el nihilismo contemporáneo, entendido como consecuencia de la desvalorización de los valores que diagnostica Nietzsche en su nihilismo europeo. La adaptación del individuo al desarraigo nihilista toma dos formas según Nishitani: una superficial y otra profunda. La adaptación superficial está marcada por el ocio, lo que conlleva ignorar o esconderse del nihilismo, lo describe como un «cripto-nihilismo». La adaptación profunda es la que caracteriza la Existenz nietzscheana y las filosofías que confrontan el nihilismo, que acaban estableciéndolo como 
la base del ser. «Entre estos dos casos cabe todo un espectro de nihilismos. Sin embargo, todos tienen en común que pertenecen al modo de ser que se sitúa decididamente en la nihilidad y apuntan a un sujeto entregado a la vitalidad simple y llana de la vida.» (Nishitani, 1999, p. 139) Son dos perspectivas que confrontan la crisis contemporánea a través de una vida sin significado.

En conclusión, el nihilismo actual es fruto del deseo de liberación que rige la labor del conocimiento científico. Nishitani continúa esta idea indicando que en la ciencia tienen una perspectiva epistemológica cuya orientación es radicalmente opuesta a la perspectiva religiosa. La orientación religiosa suele enfocar su conocimiento del mundo centrándose en la vida, y por ello acaba exaltándola. Esto demuestra porqué todas las religiones han propuesto una dimensión del ser humano que sobrevive a la muerte, el alma que va a un mundo en una segunda vida eterna, y que ambos mundos surgen de una deidad inmortal. Por el contrario, la orientación científica crece en dirección a la muerte; y prueba de ello es su interés desde los seres orgánicos hacia los seres inorgánicos. Desde la vida hacia la materia sin vida. (Nishitani, 1992, p. 145)

Esta idea de las orientaciones guarda una relación con el nihilismo europeo de Nietzsche, quien precisamente critica el predominio de la orientación religiosa y cómo esta influye en la orientación científica; ello le lleva a defender un predominio de la ciencia en todos los ámbitos, incluido en la religión, lo que conlleva su refutación y la aparición del nihilismo extremo. Posiblemente entienda la filosofía nietzscheana como desencadenante de la posición de poder de la ciencia sobre la metafísica y la religión.

El campo de la conciencia que transforma todo lo externo al sujeto en objeto, junto con el deseo y la orientación hacia lo inorgánico de la ciencia, suman los factores que desencadenan el anhelo humano de liberación de las leyes naturales, las bases de la dinámica de la mecanización, aquella que desemboca finalmente en el nuevo nihilismo. El "abismo de la nihilidad" o el pathos nihilista surge en el sujeto por una vida desarraigada con la realidad, que puede fraguarse a través 
de la superficialidad del ocio, o a través de una profundización espiritual, pero ambos casos implican una desconexión de la realidad y una apuesta por una vida simple.

\subsection{La auto-superación religiosa del nihilismo. La vacuidad-śūnyatā}

Como ya podemos evidenciar del epígrafe anterior, la autoridad de la visión científica, el deseo y la perspectiva del campo de la conciencia han de ser superados para sobrepasar este nuevo “abismo de nihilidad”. En este sentido Nishitani ofrece una reflexión que desemboca en un de punto de vista denominado perspectiva del śūnyatā, cuyo término en japonés se traduce por vacuidad.

Dos de las raíces de esta perspectiva han sido ya mencionadas en este capítulo. La primera, cuando hemos aludido a la definición de religión acuñada por Nishitani: la religión como despertar a una subjetividad más elemental que conjuga la cultura, la historia, la fe y la razón. La segunda, al exponer que el "abismo de nihilidad" surge del deseo humano como carácter teleológico del conocimiento científico.

Ese carácter teleológico para Nishitani dirige incluso nuestra vida cotidiana, pensamos toda la realidad en términos utilitaristas. En este aspecto también se establece la demarcación entre ciencia y religión: mientras que la ciencia define la vida a través de la utilidad, la religión se presenta en el momento en que la vida se considera inútil, sinsentido, en el momento nihilista y ateleológico.

\footnotetext{
«Uno puede preguntarse por la utilidad de cosas como el alimento para la vida natural o los conocimientos y las artes para la cultura. [...] nuestro modo de ser cotidiano se reduce a estos niveles de vida natural y cultural. Sin embargo, la necesidad de la religión, el hecho de que sea algo imprescindible para la vida humana consiste en que quiebra y trastoca el modo de ser cotidiano, además de devolvernos a la fuente elemental de la vida donde la vida misma es vista como inútil.» (Nishitani, 1999, p. 38)
}

En consecuencia, el pensamiento religioso emerge ante la pérdida del sentido sobre la vida y la existencia, fundamentado en la utilidad. Por eso precisamente Nishitani señala que la religión 
surge cuando el individuo se pregunta el porqué de su existencia. (Nishitani, 1999, p. 39) O lo que es lo mismo, la religión surge cuando el ser humano comienza a sufrir el "abismo de la nihilidad", cuando se duda sobre el sentido de la existencia hasta encontrar como evidente el sinsentido. Para Nishitani este sinsentido es una duda sobre la existencia sin hallar una respuesta que la justifique, por ello también define la nihilidad como «la negatividad absoluta respecto al ser de la diversidad de las cosas y los fenómenos» (Nishitani, 1999, p. 44).

Si comprendemos que toda la realidad es el mundo cambiante, donde las cosas son por tiempo limitado, entonces la negatividad del ser de las cosas queda justificada a raíz de los cambios del mundo. Es decir, las cosas son y dejan de ser, luego avanzan siempre hacia la nihilidad. De la misma manera los seres vivos habitan el mundo y dejan de hacerlo cuando mueren, cuando avanzan hacia el no-ser y dejan de existir, la muerte. Esta concepción surgida del escepticismo y del nihilismo justifica que la nihilidad sea real, como la muerte. A través de la duda sobre la existencia de todas las cosas y sobre el sentido, se alcanza una percepción de la realidad más amplia, donde se tiene en cuenta la muerte de todas las cosas, su nihilidad.

Este punto de vista que defiende Nishitani donde la realidad se ve como un mundo cambiante en el que existen el ser y su negatividad, es lo que define como campo elemental: un modo de percibir la realidad considerado más amplio que el campo de la conciencia. (Nishitani, 1999, p. 52). Lo describe como un despertar a la verdadera realidad. Un punto de vista donde encontramos la nihilidad en el fundamento de la existencia del ser. Así a través de la muerte la nihilidad también se encuentra en el fundamento de uno mismo. Es una nihilidad que afecta al sujeto.

«Este despertar implica algo más que una mera mirada contemplativa a la muerte y la nihilidad; implica que uno realiza su presencia en su propia existencia a partir de la nihilidad en el fundamento de su existencia, desde la última frontera de su propia existencia. La realización de la nihilidad, según esto, no es otra cosa que la realización del sí mismo. No se trata de observar la nihilidad objetivamente, o de concebirla en una representación, más bien 
es como si uno mismo llegara a ser esa nihilidad, y, al hacerlo, la advirtiera desde los límites de su propia existencia.» (Nishitani, 1999, p. 53)

Esta perspectiva es como podemos ver fruto de un punto de vista escéptico. La duda sobre la realidad no se responde, pero evidencia que en el mundo del devenir todas las cosas dejan de ser, incluso el propio sujeto, muerte y nihilidad forman parte de la realidad. Con esta idea nuevamente Nishitani redefine el concepto religión: el despertar a una auto-realización de la realidad, en la cual el concepto realización se entiende mediante los significados de su equivalente inglés realize, comprender y actualizar. (Nishitani, 1999, p. 41) A través de este despertar a una concepción nihilista de la realidad, se actualiza nuestra percepción del mundo y se comprende totalmente. Es un caminar desde el campo de la conciencia hacia el campo elemental.

El campo elemental de percepción de la realidad es la base de un punto de vista que percibe la nihilidad, pero desde ella el ser humano puede avanzar hacia una nueva percepción: el punto de vista de la vacuidad. Este es el camino que el individuo puede desarrollar a través del despertar de la realidad y es el punto de vista al cual Nishitani nos quiere llevar en su filosofía. El punto de vista de la vacuidad podría definirse como una concepción de la existencia donde se descubre que esa nihilidad es en verdad la «no-sustancialidad» de las cosas, su vacío. Nishitani expresa que el concepto aristotélico sustancia define los entes desde un punto de vista racional, lo que implica que se restringe al campo de la razón, de la conciencia, de esa oposición sujeto-objeto. Dicho con otras palabras, lo sustancial define al ser en cuanto es, lo que permanece por encima de sus cambios accidentales, pero su concepción no incluye la nihilidad de las cosas.

Comprendiendo que existe una concepción más amplia que concibe las cosas y su nihilidad, Nishitani considera que la esencia de las cosas debe concebir ambos aspectos. Por ello el campo elemental es el que añade la nihilidad y es el paso intermedio para alcanzar el punto de vista de la vacuidad. Este campo elemental simplemente añade el no-ser al ser, por ello lo define Nishitani como una «nada relativa», una especie de nihilidad y ser. Sin embargo, desde este punto debemos 
descubrir que en verdad esa nihilidad es una con el ser. Dicho con otras palabras, del campo elemental avanzamos a un nuevo punto de vista donde nihilidad y ser se encuentran totalmente unidos, lo que precisamente Nishitani define como una «nada-en-el-ser»o «ser-en-la-nada». En esa perspectiva deduce que la nihilidad es la mismidad del ser, la verdadera esencia de las cosas. Dado que equivale el vacío a la nihilidad, el filósofo japonés define este punto de vista con el término budista vacuidad.

«Vacuidad en el sentido de śūnyatā sólo es vacuidad cuando se vacía a sí misma, e incluso se vacía del punto de vista que la representa como alguna cosa que está vacía. En su Forma original es autovaciamiento. En este sentido, la verdadera vacuidad no es postulada como algo fuera de y otro que el ser. Más bien es realizada como algo unido e idéntico al ser.» (Nishitani, 1999. p.150)

Evidentemente, esta perspectiva de la vacuidad donde el vacío es la mismidad del ser se describe como una perspectiva religiosa. Sin embargo, para Nishitani se trata de un punto de vista que no afecta al conocimiento científico, y por ello puede albergar ambas perspectivas. En este sentido que la vacuidad aborda tanto la orientación hacia lo inorgánico como la orientación hacia lo orgánico, es decir engloba el punto de vista científico y religioso. Luego se trata de una nueva relación amistosa entre ciencia y religión. Teniendo en cuenta como la vacuidad se centra en el fundamento metafísico de las cosas, y como Nishitani concibe que la ciencia comprende la realidad hasta el límite de lo físico, descubrimos que en verdad ambos entornos no entran en conflicto en su filosofía. Que la nada sea una con el ser no afecta a como la ciencia concibe el ser.

Hay dos ideas fundamentales que podemos detectar sobre la perspectiva de la vacuidad. Primero, el fundamento de la nada no está fraguado en ninguna existencia divina, la nada no necesita causa que la genere. Por ello Nishitani destaca que la vacuidad es un modo de ver la realidad ajeno al marco teísmo/ateísmo, ni implica ni excluye a Dios. (Nishitani, 1999, p. 152). Segundo, este fundamento del ser se encuentra directamente en el mundo del devenir, es decir, no está generando un segundo mundo ontológico con un fundamento sobre el primero. No existe una 
segunda existencia vacía como fundamento del mundo del devenir. Nishitani expresamente aclara que la vacuidad no es un mundo suprasensible, en todo caso es la visión completa del mundo sensible. Esta es para él toda la realidad. (Nishitani, 1999, p. 183-184)

Siendo la vacuidad el fundamento y unidad del ser, a través de esta perspectiva se entiende una interrelación de todas las cosas, todos los seres se relacionan entre sí a través de la nada. Por tanto en último término el ser humano está obligado a no establecer diferencias subjetivas y objetivas de la realidad, donde ya hemos visto que se fundamentan las consecuencias del nihilismo contemporáneo. Al ser un fundamento que funciona a nivel científico, metafísico, filosófico y religioso, puede entenderse y aplicarse desde todos los puntos de vista existentes e incluso desde el punto de vista cotidiano. Es para él la unificación de los puntos de vista y también de las disciplinas científicas, dado que desarrolla una visión unida de la realidad, que supera la oposición sujetoobjeto. La vacuidad es tanto el fundamento de las cosas como el fundamento de uno mismo.

En definitiva, la perspectiva del campo de la conciencia entiende la realidad del sujeto no como interconectada a él, sino como separada de él. Así genera el deseo de liberación de las leyes naturales al considerar la naturaleza como objeto. Este es el principio de la dinámica que desarrolla el nihilismo contemporáneo. Desde esta opinión, Nishitani opone a ese campo de conciencia su perspectiva de la vacuidad como una auto-superación religiosa del nihilismo. Esta es de forma resumida su solución ante el problema del nihilismo contemporáneo.

\section{Conclusiones}

Antes de exponer mis conclusiones sobre esta investigación, me gustaría reseñar brevemente qué temas han quedado fuera de ella y del trabajo escrito, por motivos de espacio y tiempo.

En primer lugar, en este trabajo se ha partido de la idea de que toda la filosofía nietzscheana 
podría ser entendida como un análisis del nihilismo europeo. Sin embargo, no ha sido trabajada toda la obra de Nietzsche, sino aquellos textos de su periodo de madurez y sus últimos fragmentos personales, dado que tales textos se centran significativamente en dicha temática.

En segundo lugar, en gran parte de estos textos y fragmentos Nietzsche expone que el budismo es una forma de nihilismo incompleto. Es una cuestión de gran importancia para este trabajo que no ha podido ser abordada.

En tercer lugar y de la misma manera que en el caso de Nietzsche, la filosofía de Keiji Nishitani se ha estudiado desde sus obras dedicadas al nihilismo.

En cuarto lugar, el pensamiento de Nishitani exige de una comprensión sobre el budismo en general y especialmente sobre su rama Zen. Esta parte de la investigación se ha desarrollado, pero no ha podido ser plasmada en el texto. En cambio, la bibliografía si referencia esta cuestión. De forma personal he optado por incluir en los contenidos de este trabajo una interpretación propia del nihilismo europeo de Nietzsche, la relación vital que Keiji Nishitani tiene con el problema del nihilismo, la interpretación y superación que dicho autor realiza sobre el nihilismo europeo de Nietzsche, el nuevo diagnóstico de Nishitani sobre el problema del nihilismo contemporáneo que tiene como punto de partida las tesis de Nietzsche, y finalmente su superación del nihilismo desde una perspectiva religiosa denominada vacuidad. Ante la hipótesis que he planteado en este trabajo he considerado tales temas indispensables, y creo que son aquellos de mayor contenido filosófico. Este sumario explica la razón no haber incluido un apartado o capítulo sobre los aspectos culturales y religiosos de la filosofía de Nishitani.

En quinto y último lugar, otros muchos autores forman parte de la temática aquí trabajada, y profundizar en ellos sería indispensable para una mayor comprensión del problema: Max Stirner, Søren Kierkegaard, Karl Marx, Kitarō Nishida, Martin Heidegger y Jean Paul Sartre son algunos de los nombres que podría citar tras la investigación realizada. 
Con esto quiero decir que las conclusiones expuestas a continuación tienen un carácter provisional. Son susceptibles de ser ampliadas, corroboradas o refutadas a través de vías de investigación que trabajen tales temas señalados.

Mi conclusión final sobre la filosofía de Keiji Nishitani como forma de superar el nihilismo europeo de Nietzsche es en general negativa. En pocas palabras, Nishitani a través de su diagnóstico sobre el nihilismo contemporáneo solo ofrece su punto de vista de la vacuidad como autosuperación religiosa del problema. La auto-superación atea del nihilismo denominada Existenz queda rechazada en su última obra. Por otro lado, considero que la auto-superación religiosa a través de la vacuidad implica no solo un punto de vista como el autor define, sino además adecuarse a una serie de conceptos metafísicos y valores culturales. Solucionar el problema del nihilismo a través de Nishitani sería terminar con su perspectiva la investigación metafísica, además las sociedades tecnologicamente avanzadas tendrían que adoptar los valores culturales del budismo Zen para superarlo. Esta cuestión se centra en un punto de inflexión entre las conclusiones de la obra The Self-Overcoming of Nihilism y La religión y la nada, donde Nishitani matiza su posición con respecto a la filosofía de Nietzsche.

En ambos trabajos el aspecto del diagnóstico se encuentra claramente relacionado. Nishitani expone que la ciencia es el pensamiento que refuta la doctrina cristiana, y por ello desencadena la emergencia del nihilismo que dicha religión escondía. Desde su punto de vista este hecho genera dos consecuencias: por un lado, es el punto de partida del nihilismo europeo, pero por otro lado acentúa la separación que ya se estaba desarrollando entre la ciencia y la religión. Recordemos que la independencia de la omniabarcante autoridad científica es la clave del diagnóstico de Nishitani sobre el nihilismo contemporáneo, por ello ambos diagnósticos están entrelazados. Es decir, el nihilismo contemporáneo que Nishitani expone en La religión y la nada es un análisis de las consecuencias actuales del nihilismo europeo de Nietzsche. 
En las últimas páginas de The Self-Overcoming of Nihilism Nishitani expone la importancia de comprender el nihilismo europeo de Nietzsche como manera de identificar el nihilismo contemporáneo (Nishitani, 1990, p. 177-179). El texto en cuestión forma parte de las primeras ediciones de esta obra, cuya edición data de 1949. Por el contrario, el nuevo diagnóstico del nihilismo contemporáneo en la obra de Nishitani La religión y la nada fue escrito en 1961. De manera que, a la altura de la primera obra mencionada, Nishitani se encontraría aún reflexionando e investigando sobre la elaboración de un nuevo diagnóstico del nihilismo. Sin embargo, cuando terminó de escribir el conjunto de ensayos que forman La religión y la nada, decidió incluir el concepto Existenz como una forma introspectiva de evitar el nihilismo contemporáneo, pero no de superarlo. En ese momento está descartando la auto-superación nietzscheana y atea del nihilismo. Ese es el punto de inflexión. En ese momento la perspectiva o punto de vista de la vacuidad se fundamenta como única forma propuesta para la auto-superación del nihilismo. Dados los factores del diagnóstico, cualquier país modernizado tecnológicamente sería susceptible de sufrir el pathos nihilista contemporáneo, por ende, la extensión de sus conclusiones sobre la nihilidad podrían extenderse más allá de la sociedad occidental. El punto de vista de la vacuidad aparece entonces como la única manera de superar el problema del nihilismo para todas las demás culturas modernizadas.

En este sentido Keiji Nishitani es prudente y consecuente con la filosofía de Nietzsche. Decide inaugurar un punto de vista en lugar de una elaboración metafísica que alberga por igual el saber científico y el pensamiento religioso. En consecuencia, elabora un marco que además de percibir la realidad como totalidad, permite relacionarse con perspectivas filosóficas, científicas, religiosas y cotidianas.

Sin embargo, sería difícil justificar que la perspectiva de la vacuidad es solo un punto de vista: concibe la unidad del vacío como totalidad y esencia del ser, establece una relación de 
independencia de todas las cosas y define un campo epistemológico y experimental desde el cual percibir la realidad con tales aspectos. Debido a esto no sería capaz de pronunciarme con seguridad absoluta sobre si la vacuidad es solo un punto de vista o todo un sistema metafísico, pero en cualquier caso está cargado de conceptos metafísicos que restringen compaginar el punto de vista con otras perspectivas. De hecho, en el propio texto vemos que todas las metafísicas del campo de conciencia quedan anuladas por no ser desarrolladas desde el campo elemental. Ninguna metafísica que no se desarrolle desde la vacuidad y acepte sus fundamentos puede compaginarse con esta autosuperación del nihilismo contemporáneo. La ciencia no tendría más remedio que aceptar los límites físicos de su investigación y reconocer la esencia vacía de todas las cosas que investigan a través de sus instrumentos y métodos. Sería una restricción aceptar la vacuidad para la filosofía y la ciencia.

Esta cuestión se impone con más fuerza si la pensamos a nivel de valores religiosos y culturales. El punto de vista de la vacuidad de Nishitani bebe directamente de la religión budista Zen. Prueba de ello es que su percepción vacía es idéntica a los fundamentos de la vía media escritos por Nāgārjuna (Arnau, 2007, p. 89-90) donde se expone por ejemplo que la vacuidad es la esencia del mundo, o que todos los seres de la existencia tienen una relación de interdependencia. Estas ideas son la base de la tradición budista Mahāyāna, y de hecho Ueda Shizuteru expone que el pensamiento Zen desciende de esta tradición, albergando en su seno la idea de vacuidad como esencia de las cosas. (Shizuteru, 2004, p. 33) ¿Qué implicaría establecer el punto de vista de la vacuidad como forma de auto-superación del nihilismo contemporáneo? Pues podría ser una aculturación budista Zen de aquellas sociedades cuyas vidas han sido tecnologizadas. Esto sería problemático dado que la aculturación se ha establecido en la filosofía de Nishitani como desvalorizador de los valores, se trata de un fenómeno que podría provocar un nuevo nihilismo.

A diferencia de esta nueva terapia contra el nihilismo, la propuesta perspectivista de la filosofía nietzscheana parece presentar una solución más amplia. Permite que la solución sea una 
infinita cadena de interpretaciones sobre la existencia desde una voluntad de ilusión y a través de una serie de nuevos valores que se centran en el mundo del devenir. Es cierto que refuta totalmente la posibilidad de nuevas dimensiones de la realidad, pero aparte de eso permite una dinámica de múltiples interpretaciones cuyo objetivo es siempre fortalecer a la humanidad. Se trata de una autosuperación del nihilismo que puede ser desarrollada desde diferentes metafísicas y bases culturales.

No obstante, la filosofía de Nishitani no es rechazable absolutamente en base a esta conclusión. Para ello sería necesario en un futuro investigar el punto de vista de la vacuidad más allá de su relación con el nihilismo. Por otro lado, su diagnóstico sobre la crisis de la cultura contemporánea por el conocimiento científico y la mecanización de la vida es interesante. Personalmente reconozco que descubre una tendencia propia de las sociedades modernas: el hecho de mecanizar cada vez más sus vidas por un deseo de liberación de condiciones naturales, y además el descubrimiento de como en cierto sentido las máquinas que nos rodean controlan nuestra vida cotidiana. Evidentemente la presencia de la tecnología en nuestro día a día tiene efectos beneficiosos muy importantes, pero quizás Nishitani esté señalando precisamente cuáles son algunos de sus efectos perjudiciales. 


\section{Bibliografía}

\section{Fuentes}

NIETZSCHE, FRIEDRICH

(1873) Sobre verdad y mentira en sentido extramoral, trad. Luís ML. Valdés y Teresa

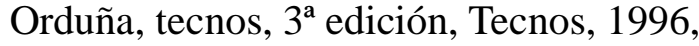

(1878) Humano, demasiado humano: Un libro para espíritus Libres. Vol. 1 y 2, trad. Alfredo Brotons Muñoz, Akal, Madrid, 2001.

(1883) La gaya ciencia, Ediciones Teorema, trad. Enrique Eidelstein, Miguel Angel Garrido y Carlos Palazón, 1985, Barcelona.

(1884) Así habló Zaratustra. $1^{\mathrm{a}}$ edición revisada, $6^{\mathrm{a}}$ reimpresión, trad. Andrés Sánchez Pascual, Madrid, Alianza, 2003.

(1885) Más allá del bien y del mal. $7^{\mathrm{a}}$ reimpresión, trad. Andrés Sánchez Pascual, Madrid, Alianza, 2005.

(1887) La genealogía de la moral, introducción, traducción y notas de Andrés Sánchez Pascual, Alianza, 1980.

(1888) Crepúsculo de los ídolos. $1^{\mathrm{a}}$ edición revisada, $3^{\mathrm{a}}$ reimpresión, trad. Andrés Sánchez Pascual, Madrid, Alianza, 2005.

Fragmentos póstumos, Volumen I, (1885-1889), Edición española dirigida por Diego Sánchez Meca, trad. De Sanchez Meca y Jesús Conill, Tecnos, Madrid, 2010.

Fragmentos póstumos, Volumen III, (1885-1889), Edición española dirigida por Diego Sánchez Meca, trad. De Sanchez Meca y Jesús Conill, Tecnos, Madrid, 2010.

Fragmentos póstumos, Volumen IV, (1885-1889), Edición española dirigida por Diego Sánchez Meca, trad. De Juan Luis Vermal, 2ª edición, Tecnos, Madrid, 2008.

NISHITANI KEIJI. 
James W. Heisig, and Raquel Bouso García. La Religión y La Nada. Vol. 18. Madrid, Siruela, 1982.

The Self-Overcoming of Nihilism, trad Graham Parkes, State University of New York, Albany, 1990.

On Buddhism. Albany: State University of New York Press, 2006.

\section{Bibliografía secundaria.}

ARNAU, JUAN, Antropología del Budismo, ed. Kairos, Barcelona, 2007.

AUGÉ, MARC, Los "no lugares" espacios del anonimato. Una antropología de la sobremodernidad, $10^{\mathrm{a}}$ reimp, trad. Margarita Mizraji, Gedisa, 2008.

\section{ÁVILA CRESPO, REMEDIOS.}

El desafío del nihilismo. La reflexión metafísica como piedad del pensar, ed. Trotta, Madrid, 2005.

Lecciones de metafísica, ed. Trotta, Madrid, 2011.

BRET-W., DAVIS, Nishitani after Nietzsche: From the Death of Go to the Great Death of the Will, en BRET-W., DAVIS, et al., Japanese and Continental Philosophy. Bloomington: Indiana University Press, 2011.

BARROSO FERNÁNDEZ, OSCAR, La antropología filosófica ante el reto del nihilismo. A propósito de Zubiri y Nietzsche; en Ávila Crespo, Remedios; Estrada Díaz, Juan Antonio; Ruiz Callejón, Encarnación (editores). Itinerarios del nihilismo. La nada como horizonte, ed. Arena Libros, Madrid, 2009.

BORGES, JORGE LUIS, Una conferencia sobre el budismo, en BORGES, JORGE LUÍS, Siete noches, edición de José C. Vázquez, ed. Meló, México, 1980.

D'ORIO, PAOLO, El eterno retorno: génesis e interpretación, en Conill-Sancho, Jesús, y 
Sánchez Meca, Diego, Guía Comares de Nietzsche, ed. Comares,Granada, 2014.

ECKEL DAVID, MALCOLM, Entender el Budismo, trad. de Maite Rodríguez Fischer, ed. Blume, Barcelona, 2004.

FERRES SERRANO, JUAN JOSÉ, Gunkan, Diccionario de Kanjis japoneses, Hiperión, Madrid, 2001.

FIGL, JOHANN, La hermenéutica transcultural: la interpretación nietzscheana de las religiones y culturas europeas, en Conill-Sancho, Jesús, Y Sánchez Meca, Diego, Guía Comares de Nietzsche, ed. Comares,Granada, 2014.

GENTILI, CARLO, Nietzsche y el cristianismo, en Conill-Sancho, Jesús, y Sánchez Meca, Diego, Guía Comares de Nietzsche, ed. Comares,Granada, 2014.

HEISIG, W. JAMES, Filósofos de la nada. Un ensayo sobre la Escuela de Kyoto, ed. Herder, Barcelona, 2002.

HISAMATSU, SHINICHI, Los Cinco Rangos Del Maestro Zen Tosan, Barcelona: Herder, 2011.

JANZ, CURT PAUL, Friedrich Nietzsche, trad. Jacobo Muñoz e Isidoro Reguera, ed. Alianza, Madrid, 1987.

JIMÉNEZ MORENO, LUIS, El pensamiento de Nietzsche, en Serie Historia de la filosofía, ed. Cincel, Madrid, 1986.

\section{LANZACO, SALAFRANCA, FEDERICO.}

Taoísmo, Budismo Zen y Cristianismo: Tres caminos de espiritualidad universal, ed. Verbum, Madrid, 2009.

Introducción a la cultura japonesa: pensamiento y religión, Universidad de Valladolid, Valladolid, 2000.

MORI TETSURÕ, Nishitani Keiji and the Question of Nationalism, en Heisig, James W., 
Rude Awakenings. Honolulu, University of Hawai Press, 1995.

NEBREDA, JESÚS J., ¿Y si la palabra nihilista no fuera sino una invención de los apóstoles del todo?, en Ávila Crespo Remedios, Estrada Díaz Juan Antonio, Ruiz Callejón Encarnación (editores). Itinerarios del nihilismo. La nada como horizonte, ed. arena libros, Madrid, 2009.

PAUL, JEAN, Alba Del Nihilismo. Edición bilingüe ed. Vol. 224. Tres Cantos, Madrid: Istmo, 2005.

PÉREZ TAPIAS, JOSÉ ANTONIO, Del bienestar a la justicia. Aportaciones para una ciudadanía intercultural, ed. Trotta, Madrid, 2007.

QUINTANILla FISAC, MIGUEL ÁNGEL, Diccionario de Filosofía Contemporánea, KRK ediciones, Oviedo, 2010.

RIVERO WEBER, PAULINA, Nietzsche y el Tao. Nihilismo nietzscheano y nihilismo taoísta, en Javier de la Higuera, L. Sáez, José F. Zúñiga, Nihilismo y Mundo actual, ed. Universidad de Granada, Granada, 2009.

SÁNCHEZ MECA, DIEGO. El Nihilismo. Perspectivas Sobre La Historia Espiritual De Europa. Vol. 13. Madrid: Síntesis, 2004.

SANCHEZ MECA, DIEGO, Figuras del Ultrahombre (ய̈bermensch) nietzscheano, en Conill-Sancho, Jesús, y Sánchez Meca, Diego, Guía Comares de Nietzsche, ed. Comares,Granada, 2014.

SHIZUTERU UEDA, Zen y filosofía, trad. Raquel Bouso García e Illana Giner Comín, Herder, Barcelona, 2004.

SUZUKI, DAISETZ TEITARO:

¿Qué es el Zen?, edición, traducción del inglés, prólogo y notas, por Carlos Vergara, ed. Losada, Madrid, 2006. 
Ensayos Sobre Budismo Zen, (Segunda Serie), $4^{\mathrm{a}}$ reimp ed. Kier, Buenos Aires, 2007.

TURGUENIEV, SERGEIEVICH, Padres e hijos, en Maestros Rusos. Novelas-Relatos, Volumen II, primera edición, ed. Planeta, Barcelona, 1960.

UEDA, SHIZUTERU, Raquel Bouso García, and Illana Giner Comín. Zen y filosofía, Herder, Barcelona, 2004.

VALLEJO CAMPOS, ÁLVARO, De Nietzsche a Heidegger: Platón y el problema del nihilismo, en L. Saéz, J. De la Higuera y J.F. Zúñiga (Eds.) Pensar la Nada. Ensayos sobre filosofía y nihilismo, ed. Biblioteca Nueva, Madrid, 2007.

VOLPI, FRANCO, El nihilismo, trad. De Cristina I. del Rosso y Alejandro G. Vigo, nueva edición revisada, 2004, ed. Biblos, Buenos Aires, 2005. 